\title{
Evaluation of Satellite Precipitation Products and Their Potential Influence on Hydrological Modeling over the Ganzi River Basin of the Tibetan Plateau
}

\author{
Alaa Alden Alazzy, ${ }^{1}$ Haishen Lüi, ${ }^{1}$ Rensheng Chen, ${ }^{2}$ Abubaker B. Ali, ${ }^{3}$ \\ Yonghua Zhu, ${ }^{1}$ and Jianbin $\mathrm{Su}^{1}$ \\ ${ }^{1}$ State Key Laboratory of Hydrology-Water Resources and Hydraulic Engineering, College of Hydrology and Water Resources, \\ Hohai University, Nanjing 210098, China \\ ${ }^{2}$ Northwest Institute of Eco-Environment and Resources, Chinese Academy of Sciences, Lanzhou, Gansu 730000, China \\ ${ }^{3}$ Research Center of Fluid Machinery \& Engineering, National Research Center of Pumps, Water Saving Irrigation, Jiangsu University, \\ Zhenjiang 212013, China
}

Correspondence should be addressed to Alaa Alden Alazzy; azzy22@hotmail.com and Haishen Lü; haishenlu@foxmail.com

Received 20 November 2016; Revised 26 January 2017; Accepted 1 February 2017; Published 30 March 2017

Academic Editor: Gwo-Fong Lin

Copyright ( 2017 Alaa Alden Alazzy et al. This is an open access article distributed under the Creative Commons Attribution License, which permits unrestricted use, distribution, and reproduction in any medium, provided the original work is properly cited.

In the last few years, satellite-based precipitation datasets are believed to be a potential source for forcing inputs in driving hydrological models, which are important especially in complex terrain areas or ungauged basins where ground gauges are generally sparse or nonexistent. This study aims to comprehensively evaluate the satellite precipitation products, CMORPH-CRT, PERSIANN-CDR, 3B42RT, and 3B42 against gauge-based datasets and to infer their relative potential impacts on hydrological processes simulation using the HEC-HMS model in the Ganzi River Basin (GRB) of the Tibetan Plateau. Results from a quantitative statistical comparison reveal that, at annual and seasonal scales, both CMORPH-CRT and 3B42 perform better than PERSIANN$\mathrm{CDR}$ and 3B42RT. The CMORPH-CRT and 3B42 tend to underestimate values at the medium and high precipitation intensities ranges, whereas the opposite tendency is found for PERSIANN-CDR and 3B42RT. Overall, 3B42 exhibits the best performance for streamflow simulations over GRB and even outperforms simulation driven by gauge data during the validation period. PERSIANNCDR shows the worst overall performance. After recalibrating with input-specific precipitation data, the performance of all satellite precipitation forced simulations is substantially improved, except for PERSIANN-CDR. Furthermore, 3B42 is more suitable to drive hydrological models and can be a potential alternative source of sparse data in Tibetan Plateau basins.

\section{Introduction}

Water resources management in remote regions or heterogeneous terrains, particularly for the mountain river basins, is one of the most important challenges facing decisionmakers and hydrologists due to the extreme scarcity of in situ monitoring stations, leading to dramatic effects on the ecological, agricultural, and economic activities [1]. However, hydrological modeling can play a helpful role in effective water resources management under the absence of hydrological data [2], but there is still an urgent need to overcome the problematic lack of in situ meteorological data (i.e., precipitation, temperature, and wind speed) for many hydrological, hydrometeorological, and climatological applications.

Among these components, precipitation is one of the necessary forcing inputs of the global water cycle that cannot be exempt and is essential in order to satisfy requirements for calculating various land surface hydrological models. Additionally, the precision of precipitation measurements at spatiotemporal representations has a great influence on the effective predictions of hydrological models [3, 4], as highly accurate representations may reduce the uncertainties in simulating the hydrological processes of watersheds $[5,6]$.

A conventional approach in estimation of precipitation amount involves meteorological radar observations and/or 
rain gauges observations, whereas in the less accessible regions or complex terrains of the world, notably on the Tibetan Plateau, the contributions to hydrological literature have already explained the weakness of ground-based measurement networks in the representation of precipitation systems, due to the deformation of the radar signals and insufficient density of gauges as well as relatively high spatial variability of precipitation [7-9].

A conventional approach for estimating the quantity of precipitation involves meteorological radar observations and/or rain gauge observations. However, in the less accessible regions or complex terrains of the world, such as the Tibetan Plateau, the hydrological literature has already explained the weakness of ground-based measurement networks in the representation of precipitation systems due to the deformation of the radar signals, insufficient density of gauges, and relatively high spatial variability of precipitation [7-9].

To compensate for these disadvantages, remotely sensed precipitation datasets have been extensively used as alternative sources for gauged-based techniques over the last decade, particularly for various hydrological applications, such as flood forecasting and control, early drought warning, and streamflow simulation in ungauged basins [10, 11].

However, satellite precipitation estimates always suffer from uncertainties which arise from measurement errors associated with observations, sampling, retrieval algorithms, and bias correction processes $[12,13]$. Consequently, it is essential to verify the quality and applicability of multisatellite precipitation products using both quantitative statistical and hydrological modeling evaluation strategies [14-17], which can be useful tools for further improvement in the satellite retrieval algorithms [18] and determining which of the different satellite-based precipitation datasets should be favored for hydrological applications [19].

At present, satellite-based precipitation products have become operationally available at high spatial $\left(\leq 0.25^{\circ}\right)$ and temporal $(\leq 3 \mathrm{~h})$ resolutions over quasi-global scales. In this context, some notable products of the latest satellite precipitation technology include the NOAA's Climate Prediction Center (CPC) Morphing technique-bias-corrected product (CMORPH-CRT) [20], the Precipitation Estimation from Remotely Sensed Information Using Artificial Neural Networks-Climate Data Record (PERSIANN-CDR) [21], and the Tropical Rainfall Measuring Mission (TRMM) Multisatellite Precipitation Analysis (TMPA) products (3B42 and 3B42RT) [22]. To the authors' knowledge, these newly available products have not been thoroughly explored in mountainous basins, which are characterized by complex terrains and high elevations, especially in ungauged basins of the Tibetan Plateau.

In recent years, numerous researches have been conducted to analyze the performances of high satellite products over the Tibetan Plateau. These previous publications can be grouped according to two trends: The first trend most commonly has focused on the comparison and evaluation of satellite products against ground-based estimates, used not only to investigate temporal characteristics and spatial distributions, but also to analyze the error quantification associated with them. Notably, Gao and Liu [23] evaluated four satellite precipitation products, namely, 3B42 V6, 3B42RT V6, CMORPH, and PERSIANN, with 166 rain gauges at a daily scale throughout the Tibetan Plateau. The study revealed that the performance of 3B42 and CMORPH is better than 3b42RT and PERSIANN, especially in humid regions. Unlike CMORPH and 3B42, it was found that the biases of 3B42RT and PERSIANN significantly depended on topography and variability of elevation and surface roughness. In another study, Li et al. [24] compared four satellite products, including 3B42 V7, 3B42 V7, CMORPH, and PERSIANN, with gauge observations from the China Meteorological Administration (CMA) at multiple time scales over the Yangzi River Basin, and the results showed that gauge adjustment in 3B42 V7 greatly reduces the bias, but $3 \mathrm{~B} 42 \mathrm{~V} 7$ is not always superior to other products (especially CMORPH) at a daily scale. Jiang et al. [25] also compared the four 3B42 V7, 3B42RT V7, CMORPH, and CMORPH-CRT satellite precipitation products against gauge observations of the Yellow River Basin at different spatial and temporal scales, which indicated that each of the four products were able to effectively detect precipitation events and that the $3 \mathrm{~B} 42$ product performance was better than others overall.

The second trend of studies evaluates the hydrological utility of satellite products based on their potential use in diverse hydrologic studies, especially for driving hydrologic models. Among these studies, Tong et al. [8] investigated the streamflow simulation abilities of 3B42V7, 3B42RTV7, CMORPH, and PERSIANN using the Variable Infiltration Capacity (VIC) hydrologic model in the upper Yellow and Yangtze River Basins on the Tibetan Plateau. Their study reported that $3 \mathrm{~b} 42 \mathrm{~V} 7$ had comparable performance to CMA data in both monthly and daily streamflow simulations; while 3B42RTV7 and PERSIANN exhibited little capability for streamflow simulation in hydrological study, the CMORPH showed some potential for use in hydrological applications over these regions. In another study, PERSIANN-CDR was used by Liu et al. [26] to assess the capability of streamflow simulation with the hydroinformatic modeling system (HIMS) rainfall-runoff model for the upper Yellow River Basin and the upper Yangtze River Basin. Results concluded that the PERSIANN-CDR was suitable to simulate reasonably good streamflow in basins of the Tibetan Plateau and also has potential to be an alternative source of the sparse gauge network for future hydrological and climate change studies. In another example, Li et al. [27] focused on the potential use of 3B42V7, 3B42RTV7, and CMORPH products for simulating hydrological processes via a geomorphology-based hydrological model (GBHM) over the Yangtze River Basin. The study suggested that $3 \mathrm{~b} 42 \mathrm{~V} 7$ performed best for annual water budgeting and monthly streamflow simulation; however this model displayed evident weakness in performance for daily simulation. The study also found that 3B42RTV7 tends to perform better than CMORPH for streamflow modeling, particularly in the midstream and downstream tributaries of the Yangzi River.

Unfortunately, the majority of these previous efforts were generally limited to large key river basins, such as the Yangtze River Basin and the Yellow River Basin, and 
there are no thorough investigations in mesoscale basins, especially so in the ungauged regions of the southeast Tibetan Plateau, which may be associated with poor performance of satellite precipitation estimates in hydrological simulations as compared to those of large basins [5, 28]. Additionally, the applicability of the latest satellite precipitation datasets for hydrological modeling framework, including 3B42, 3B42RT, PERSIANN-CDR, CMORPH-CRT, seems to lack adequate coverage in the literature, especially for the Ganzi River Basin (GRB) in the southeast Tibetan Plateau.

Considering these issues, the specific research objectives of this study are to (i) evaluate and compare the capability of the latest four satellite precipitation products to characterize precipitation patterns and capture the magnitude of precipitation events over GRB; (ii) investigate the use potential and limitations of satellite precipitation estimates as forcing inputs in driving the HEC-HMS model; (iii) investigate their influence on the simulation of daily hydrological processes at the basin scale.

The rest of the article is structured as follows: Section 2 presents a brief overview of the study area and datasets used. Section 3 provides a description of the HEC-HMS hydrological model, followed by a detailed discussion of the calibration procedures and simulation scenarios for the hydrologic model and then lists statistical criteria of its performance evaluation. The results of the comprehensive evaluations of the four satellite estimates and their hydrological utilities are compared and discussed in Section 4. Finally, the conclusions and summary of this study are given together with some advice for future studies in Section 5.

\section{Study Area and Datasets Description}

2.1. Study Area. The region under study focuses on the GRB located at upper part of the Yalong River in southeastern Qinghai-Tibetan Plateau, China, as shown in Figure 1(a). The GRB covers a drainage area of approximately $32925 \mathrm{Km}^{2}$ and extends across the geographical range from $31.5^{\circ}$ to $34.25^{\circ}$ northern latitude and from $96.75^{\circ}$ to $100^{\circ}$ eastern longitude. The average altitude of the drainage area is around $4500 \mathrm{~m}$ with the highest elevation of $6102 \mathrm{~m}$ in the western and upper part of the basin and lowest elevation of $3394 \mathrm{~m}$ in the southeastern plains.

The basin is a cold and dry climate zone characterized with a dry winter and a rainy summer. The average annual maximum and minimum temperature within the region are about $15^{\circ} \mathrm{C}$ and $-10^{\circ} \mathrm{C}$, respectively. The highest temperature of $31^{\circ} \mathrm{C}$ is detected in July, and the lowest temperature of $-28.9^{\circ} \mathrm{C}$ in January. The average annual precipitation reaches $650 \mathrm{~mm}, 90 \%$ of which occurs during rainy season (from May to October) and $10 \%$ in the rest of the year. The snowfall contribution of the total annual precipitation ranges from $50 \%$ in the relatively high areas to less than $30 \%$ in the low lying areas. The basin considered in this study is affected by solid precipitation when the temperature is less than or equal to $0^{\circ} \mathrm{C}$. The average annual discharge at the GBR's outlet is about $290.82 \mathrm{~m}^{3} \mathrm{~s}^{-1}$ with a maximum discharge amounting to $1820 \mathrm{~m}^{3} \mathrm{~s}^{-1}$, which occurred in the period between 1 January 2000 and 31 December 2012.
The land use and land cover classes consist of various types in the GBR, with croplands, herbaceous vegetation, grassland, forest, and bare areas being the main types. The distribution of land use ranges from croplands in the central and lower areas of the GBR to grassland and herbaceous vegetation in the upper areas (Figure 1(b)). Soil types of the watershed are dominated by Leptosols (82\%), Gleysols (7\%), Cambisols (5\%), and Greyzems (3\%). Other types include Histosols, Luvisols, Phaeozems, and Glaciers, and ice covers $3 \%$ of the total area (Figure $1(\mathrm{c})$ ).

2.2. Datasets Description. In the current study, due to restrictions on the availability of the rain gauge observations over the GRB, we have selected the derived datasets from satellites and ground gauges over a six-year period from 1st January 2008 to 31st December 2013. The choice of this period is attributed to the availability of both satellite and gauged precipitation datasets.

2.2.1. Gauge-Based Synthesis Datasets. The historical records of daily datasets were collected from three meteorological ground-based stations, which consist of maximum and minimum air temperature, precipitation, and evapotranspiration; in particular the gauged precipitation estimates are first used as the reference datasets to evaluate the satellite-based precipitation products. Figure 1 shows the distribution of these stations over the GRB, and Table 1 summarizes their basic information involving latitude, longitude, altitude, average annual precipitation, and average annual $\mathrm{min} / \mathrm{max}$ temperature. Besides meteorological observations, daily observed streamflow records at the outlet of the GRB were collected from the Ganzi hydrological station. Besides meteorological observations, daily observed streamflow records at the outlet of the GRB were collected from the Ganzi hydrological station. Besides meteorological observations, daily observed streamflow records at the outlet of the GRB were collected from the Ganzi hydrological station.

In this study, all meteorological and hydrological datasets were reported during the period 2008-2013, which are used as forcing inputs into the HEC-HMS model to generate streamflow simulations. It is also noteworthy that, not only to ensure effective and efficient comparison of the four satellite precipitation products versus gauge-based precipitation data but also to satisfy the requirement of the HECHMS hydrologic model inputs, the daily basin averaged precipitation was conducted by using the Thiessen polygon method, which is recommended as one of the simplest and most robust interpolation methods by Grayson and Bloschl [29].

2.2.2. Satellite-Based Precipitation Datasets. In this section, we discuss the main characteristics of the four different satellite-based precipitation products used and investigate their suitability to capture precipitation patterns and extremes over GRB. These precipitation datasets were considered to be appropriate in this study because of their high spatial and temporal resolution, coverage domain, and periods availability. A description of these products is summarized as follows. 


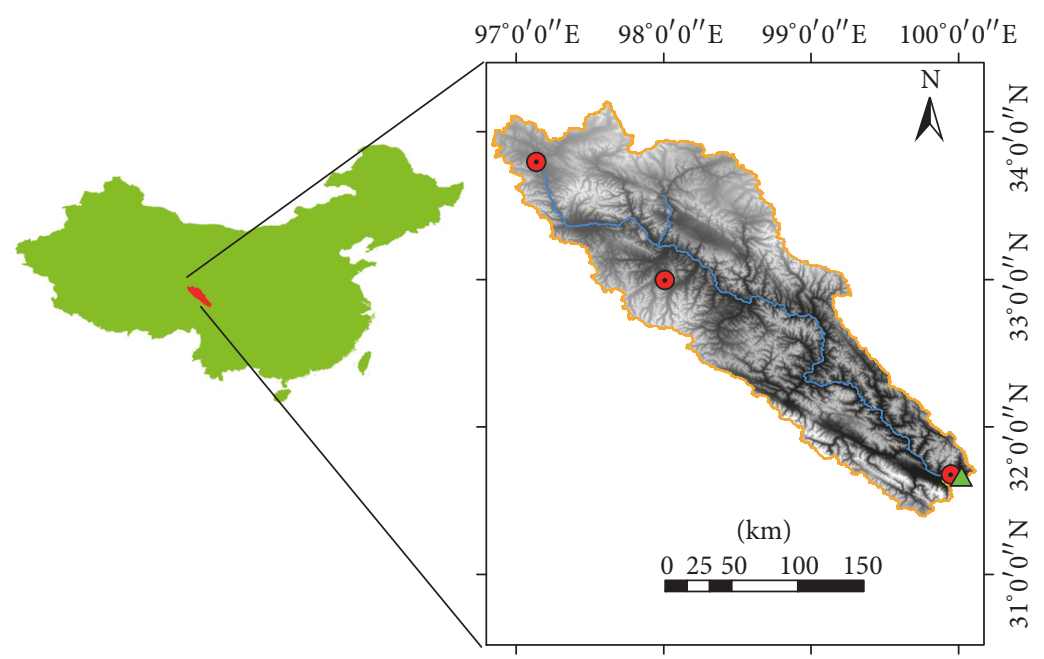
$\triangle$ Hydrological station
Elevation (m)
- Meteorological station
High: 6102
River
Low: 3344

(a)
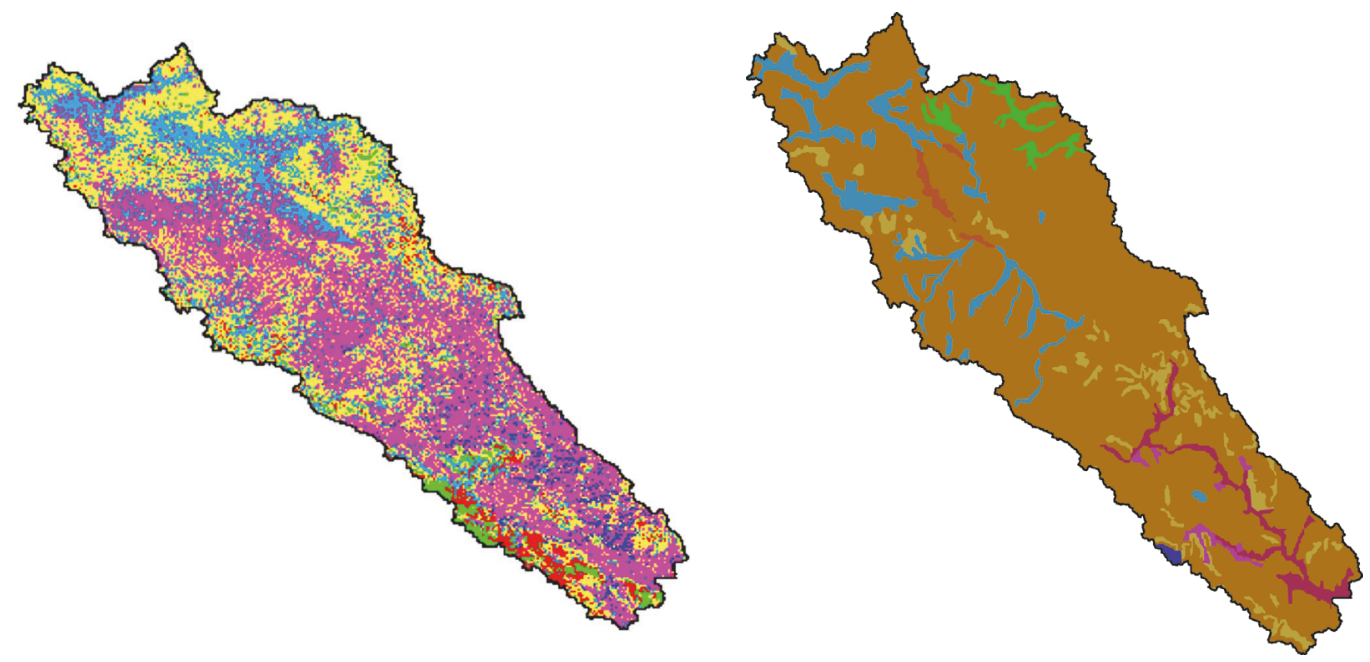

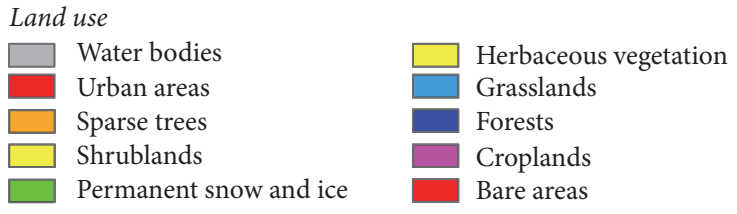

(b)

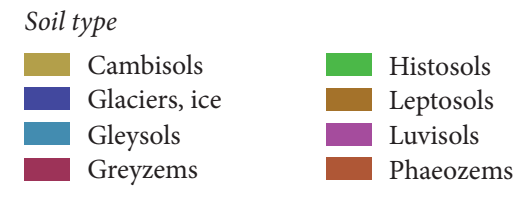

(c)

FIGURE 1: (a) (left) Location of GRB in China with meteorological and hydrological stations and (right) the DEM map of GRB; (b) land use; and (c) soil type.

TABLE 1: The main characteristics of meteorological ground-based stations across GRB.

\begin{tabular}{lcccccccc}
\hline Number & ID & Station name & $\begin{array}{c}\text { Latitude } \\
\left({ }^{\circ} \mathrm{N}\right)\end{array}$ & $\begin{array}{c}\text { Longitude } \\
\left({ }^{\circ} \mathrm{E}\right)\end{array}$ & $\begin{array}{c}\text { Altitude } \\
(\mathrm{m})\end{array}$ & $\begin{array}{c}\text { Average annual } \\
\text { precipitation } \\
(\mathrm{mm})\end{array}$ & $\begin{array}{c}\text { Average annual } \\
\text { min temperature } \\
\left({ }^{\circ} \mathrm{C}\right)\end{array}$ & $\begin{array}{c}\text { Average annual } \\
\text { max temperature } \\
\left({ }^{\circ} \mathrm{C}\right)\end{array}$ \\
\hline 1 & 56034 & Qinshuihe & 33.80 & 97.13 & 4426 & 598.83 & -9.79 & 5.03 \\
2 & 56038 & Shiqu & 32.98 & 98.01 & 4200 & 623.11 & 6.28 & 6.45 \\
3 & 56146 & Ganzi & 31.61 & 100.02 & 3394 & 670.10 & 0.34 & 14.87 \\
\hline
\end{tabular}


(i) CMORPH-CRT. The CMORPH technique [30] uses two types of data to estimate precipitation, including passive microwave (PWM) observations obtained from Low Earth Orbiting (LEO) satellite radiometers and infrared (IR) observations obtained from geostationary satellites. The approach relies primarily on PMW data to generate precipitation estimates with propagation by morphing algorithm, which is used to derive a cloud motion field from IR imageries at geostationary satellites. The time-weighted linear interpolation on this technique has been used in modifying the shape and intensity of the precipitation systems based on weights from forward and backward advection of precipitation patterns with the competent temporal distance of PMW data (initial and subsequent).

In particular, CMORPH is one type of near real-time satellite products, for which estimates are available about 18 hours past real-time. Data are available at various temporal and spatial resolutions, including 30 minute at $\sim 8 \mathrm{~km}$ resolution, 3-hourly at $0.25^{\circ}$ lat/lon resolution, and daily at $0.25^{\circ}$ lat/lon resolution.

Recently, the NOAA-CPC has produced new satellite precipitation datasets, called CMORPH Version 1.0. The main differences between the old version $0 . x$ and the latest version 1.0 can be summarized as follows: The fixed algorithm and satellite precipitation datasets of fixed versions over the entire TRMM/GPM era (1998-present) were used, especially to ensure best possible homogeneity, in the latest version 1.0, whereas since 2002 the old version 0.x has been established using varied improving algorithms and changing versions of satellite-based precipitation products inputs [20].

Moreover, the CMORPH Version 1.0 datasets are available in the form of three products: a pure satellite precipitation product (CMORPH-RAW) as well as bias-corrected product (CMORPH-CRT), and gauge-satellite blended product (CMORPH-BLD), while the old version 0.x exclusively contains satellite only precipitation product [31].

Hence, 1-daily $0.25^{\circ} \times 0.25^{\circ} \mathrm{CMORPH}$-CRT product is validated over GRB using gauged precipitation observations. The datasets in this study were freely obtained from the agency of the NOAA-CPC website (ftp://ftp.cpc.ncep.noaa .gov/precip/CMORPH_V1.0/). The main feature of the CMORPH-CRT is that the probability density function (PDF) matching was used to conduct bias correction through adjusting the original $\mathrm{CMORPH}$ satellite precipitation estimates against the CPC unified daily gauge analysis over land and the pentad GPCP analysis over ocean [32]. A full description of the CMORPH-CRT analysis and its applications has been provided by Xie et al. [31] and Xie et al. [32].

(ii) PERSIANN-CDR. The original PERSIANN, first established by Hsu et al. [33] at the University of California, Irvine, is one of the popular satellite-based precipitation algorithms for estimating historical precipitation from March 2000 to present. The PERSIANN algorithm has been developed by combining IR and PMW observations from Geostationary Earth Orbiting (GEO) and Low Earth Orbit (LEO) satellite imagery, respectively, for global precipitation estimation. Depending on an Artificial Neural Network (ANN) model in the PERSIANN algorithm, the local cloud textures provided by the geostationary satellite longwave infrared images ( $10.2-11.2 \mu \mathrm{m}$ ) approach are used to estimate surface rainfall rates, and it updates its network parameters based on the TMI2A12 product from the low-inclination orbiting TRMM satellite [34].

Compared to its existing product, the latest PERSIANNCDR (PERSIANN-Climate Data Record) product was newly developed by Ashouri et al. [21] as a multisatellite, highresolution, and posttime precipitation product. The PERSIANN-CDR product first used the archive of the Gridded Satellite (GridSat-B1) IR data [35] as the input to the trained PERSIANN model; then the biases in the PERSIANNestimated precipitation were adjusted by the Global Precipitation Climatology Project (GPCP) monthly $2.5^{\circ}$ product version 2.2 [21].

Since no PMW is used in PERSSIAN-CDR product, the ANN model parameters were pretrained using the National Centers for Environmental Prediction (NCEP) stage IV hourly precipitation data; then the model is run using the full historical record of GridSat-B1 IR data with fixed model parameters as those reported in a calibration scheme by Ashouri et al. [21].

Currently, this version of PERSIANN-CDR is only available with high spatial resolution of $0.25^{\circ} \times 0.25^{\circ}$ and daily temporal resolution. The precipitation datasets, from 1st January 1983 to present, have been collected and distributed by the NOAA's National Climatic Data Center (NCDC), as well as the Center for Hydrometeorology and Remote Sensing (CHRS) at the University of California, Irvine. In this study, the PERSIANN-CDR product datasets of the entire study period were downloaded from ftp://data.ncdc.noaa.gov/cdr/ persiann/files/. More information on PERSIANN-CDR product can be found in $[21,36]$; thus this article only gives a brief description.

(iii) TMPA 3B42V7 and 3B42RT. The TMPA product [37] was launched in November 1997, jointly between the National Space Development Agency (NASDA) of Japan and the National Aeronautics and Space Administration (NASA) of the United States. It is designed primarily to monitor and study tropical precipitation for weather and climate research.

According to Huffman et al. [22], the accurate precipitation estimates of satellite TMPA were produced by merging three types of observations such as PMW, IR, and PR from multiple LEO and Geo satellites and ground observations at a spatial resolution of $0.25^{\circ} \times 0.25^{\circ}$, with a temporal resolution of 3-hourly; however, PR, PMW, and IR operate within the global latitude belt from over $35^{\circ} \mathrm{N}$ to $35^{\circ} \mathrm{S}, 40^{\circ} \mathrm{N}$ to $40^{\circ} \mathrm{S}$, and $50^{\circ} \mathrm{N}$ to $50^{\circ} \mathrm{S}$, respectively. Thus, the TMPA algorithm could be executed using the following three steps: first, the PMW precipitation estimates are calibrated and combined to generate the most accurate estimation from PMW; second, the calibrated PMW are used to create IR precipitation estimates; and finally, both the PMW and IR precipitation estimates are merged to provide the best TMPA precipitation estimates.

In this research, the TMA product's latest version 7 was employed, which was released in May 2012 by the NASA 
TABLE 2: Summary of the selected satellite-based precipitation products used in the present study.

\begin{tabular}{|c|c|c|c|c|}
\hline Datasets & CMORPH-CRT & PERSIANN-CDR & $3 \mathrm{~B} 42$ & 3B42RT \\
\hline Spatial resolution & $0.25^{\circ} \times 0.25^{\circ}$ & $0.25^{\circ} \times 0.25^{\circ}$ & $0.25^{\circ} \times 0.25^{\circ}$ & $0.25^{\circ} \times 0.25^{\circ}$ \\
\hline Temporal resolution & 1 daily & 1 daily & 3 hourly & 3 hourly \\
\hline Spatial coverage & $\begin{array}{c}180^{\circ} \mathrm{W}-180^{\circ} \mathrm{E}, 60^{\circ} \mathrm{N}-60^{\circ} \mathrm{S} \\
\text { Quasi-global }\end{array}$ & $\begin{array}{c}180^{\circ} \mathrm{W}-180^{\circ} \mathrm{E}, 60^{\circ} \mathrm{N}-60^{\circ} \mathrm{S} \\
\text { Quasi-global }\end{array}$ & $\begin{array}{c}180^{\circ} \mathrm{W}-180^{\circ} \mathrm{E}, 50^{\circ} \mathrm{N}-50^{\circ} \mathrm{S} \\
\text { Quasi-global }\end{array}$ & $\begin{array}{c}180^{\circ} \mathrm{W}-180^{\circ} \mathrm{E}, 50^{\circ} \mathrm{N}-50^{\circ} \mathrm{S} \\
\text { Quasi-global }\end{array}$ \\
\hline Temporal coverage & 1998-present & 1983-present & 1998-present & 2002-present \\
\hline Datasets source & $\begin{array}{l}\text { Geostationary IR, PMW, } \\
\text { TMI, SSM/I, AMSR-E, } \\
\text { and AMSU-B }\end{array}$ & $\begin{array}{l}\text { Geostationary IR, PMW, } \\
\text { TMI, SSM/I, AMSU-B, } \\
\text { and ANN }\end{array}$ & $\begin{array}{c}\text { Geostationary IR, PMW, TCI, } \\
\text { SSM/I, AMSR-E, and } \\
\text { AMSU-B }\end{array}$ & $\begin{array}{l}\text { Geostationary IR, PMW, } \\
\text { TMI, SSM/I, AMSR-E, } \\
\text { and AMSU-B }\end{array}$ \\
\hline $\begin{array}{l}\text { Data download } \\
\text { website }\end{array}$ & $\begin{array}{c}\mathrm{ftp}: / / \mathrm{ftp} . c p c . n c e p . n o a a \\
\text {.gov/precip/CMORPH_ } \\
\text { V1.0/ }\end{array}$ & $\begin{array}{l}\text { ftp://data.ncdc.noaa.gov/ } \\
\text { cdr/persiann/files/ }\end{array}$ & $\begin{array}{l}\text { https://giovanni.sci.gsfc. } \\
\text { nasa.gov/giovanni/ }\end{array}$ & $\begin{array}{l}\text { https://giovanni.sci.gsfc. } \\
\text { nasa.gov/giovanni/ }\end{array}$ \\
\hline Reference & Xie et al. (2013) & Ashori et al. (2015) & Huffman et al. (2010) & Huffman et al. (2010) \\
\hline
\end{tabular}

IR: infrared radiance; PM: passive microwave; TMI: TRMM Microwave Imager; TCI: TRMM Combined Instrument; AMSR-E: Advanced Microwave Scanning Radiometer-Earth Observing Systems; SSM/I: Special Sensor Microwave Imager; AMSU-B: Advanced Microwave Sounding Unit-B; ANN: Artificial Neural Network.

Goddard Earth Sciences Data and Information Services Center (GES DISC). The substantial improvement of the TMPA version 7 product is attributed to a combination of factors including the following: (1) The inclusion of additional satellite datasets, such as the Microwave Humidity Sounder (MHS), the entire operational Special Sensor Microwave Imager/Sounder (SSM/IS), and the Grisat-B1 IR datasets [38]; (2) using the uniformly reprocessed input data, surface precipitation gauge analysis, and a latitude-band calibration scheme for all satellites [39].

It is known that the TMPA version 7 consists of two standard products: near real-time version (3B42RT, hereafter) and post-real-time version (3B42, hereafter), which are summarized here. The 3B 42 provides the bias-corrected precipitation estimates by inclusion ground gauge observations from the Global Precipitation Climatology Center (GPCC) and the Climate Assessment and Monitoring System (CAMS) at the monthly scale. The 3B42 is therefore available about 10-15 days after the end of each month, while the $3 \mathrm{~B} 42 \mathrm{RT}$ is available approximately nine hours after realtime observations, making it especially suitable to flood forecasting researches. The main difference is that the TRMM Combined Instrument (TCI) dataset has been used in 3B42 for calibration; however, it was replaced by the TRMM Microwave Imager (TMI) dataset in 3B42RT. The 3B42 and 3B42RT products have been utilized since January 1998 and March 2003, respectively, with a $0.25^{\circ} \times 0.25^{\circ}$ spatial resolution and a 3 -hourly temporal resolution. For detailed information regarding the 3B42 and 3B42RT products, the reader is referred to Huffman and Bolvin [40, 41].

However, both the $3 \mathrm{~B} 42$ and 3B42RT data used in this study were freely obtained from the following website: https://giovanni.sci.gsfc.nasa.gov/giovanni/. It is worthwhile to mention that both the 3B42 and 3B42RT precipitation datasets were aggregated into daily scale before use due to the hydrologic model requiring daily input data as well as for being needed for comparison objectives. Overall, the four satellite products (CMORPH-CRT, PERSIANN-CDR, 3B42RT, and 3B42) were considered in this study, since they have not been previously evaluated and tested over the GRB. Further details on the nature of the four satellites are presented in Table 2.

\section{Methodology}

3.1. HEC-HMS Hydrologic Model. The hydrologic model used in this study is the Hydrologic Engineering CenterHydrologic Modeling System (HEC-HMS) model [42, 43], which is well known as the semidistributed conceptual hydrologic model. The model has been extensively and successfully documented in much of the hydrological watersheds under climate conditions (humid, tropical, subtropical, etc.), since its development in the 1989s [44-46].

This study used HEC-HMS version 4 which was recently developed in 2013 [42]. To set up HEC-HMS to simulate hydrologic processes for GRB, the model input requires a Digital Elevation Model (DEM), meteorological data, soil type, and land use. DEM data with spatial resolution of $30 \mathrm{~m}$ was generated from the U.S. Geological Survey (USGS) (https:/gdex.cr.usgs.gov/gdex/). Land use data was obtained from the GlobCover 2009 land cover map (http://due.esrin .esa.int/page_globcover.php). Soil map was derived from the soil and terrain (SOTER) database developed by FAO and the International Soils References and Information Center (ISRIC) (http://www.isric.org/data/soil-and-terraindatabase-china).

In the Geospatial Hydrologic Modeling Extension (HECGeoHMS) version 10.1 with ArcHydro extension in ArcGIS 10.2, the GRB was divided into fifty-one subbasins connected by a stream network (twenty-five reaches and twenty-five junctions) based on available DEM data, and all initial values of the model parameters were calculated, which were further used as the hydrologic input files for an HEC-HMS project. Figure 2 shows the schematic diagram of HEC-HMS of the GRB after delineating, using HEC-GeoHMS. For a more detailed description of HEC-GeoHMS, see the user's manual for HEC-GeoHMS version 10.1 [47].

There are three main components in HEC-HMS including basin model, meteorological model, and control 


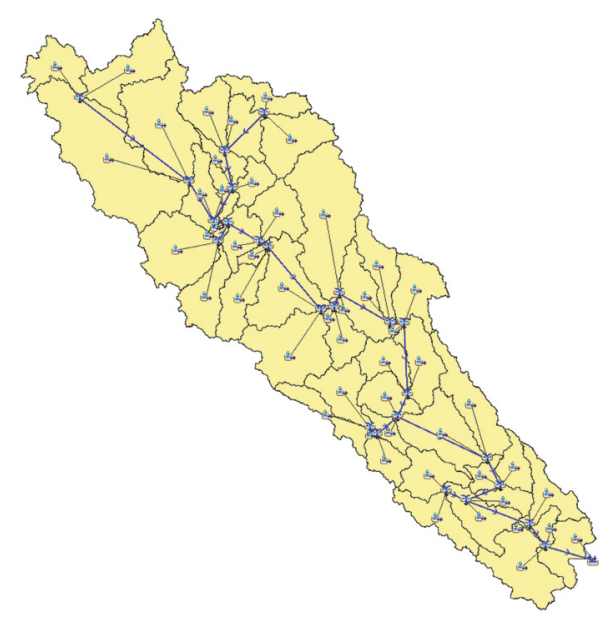

Figure 2: The schematic diagram of GRB with hydrologic elements (subbasins, reaches, junctions, and flow direction) delineated by HEC-GeoHMS.

specifications. The physical characteristics of the watershed and connectivity data are described in the basin model. The meteorological boundary conditions such as precipitation, snowmelt, and evapotranspiration data for the subbasins are prepared in the meteorological model. The time period of a simulation run is determined in the control specifications which include a starting date and time, an ending date and time, and a computation time step. The hydrologic simulation process requires a combination of datasets for each model. For a detailed description of the HEC-HMS simulation mechanisms, the reader is referred to HECHMS user's manual [42] and the Technical Reference Manual [43]; therefore, only a brief description is provided here.

The streamflow simulations of watershed in the HEC-HM model are carried out in four different runoff components: rainfall loss component; surface runoff component; baseflow component; and river routing component. In this study, the following methods are applied: (i) the deficit and constant loss (DCL) method for computing the actual infiltration losses, (ii) the Clark unit hydrograph method for transforming direct runoff of excess precipitation on a watershed, (iii) the exponential recession method for specifying the subsurface flow rates, and (iv) the Muskingum routing method for flow routing in each reach.

Additionally, the temperature index snowmelt method was used to measure runoff from snowfall by determining the volume of snow water equivalent (SWE), which is the depth of water from melting a unit column of the snowpack. This method included in the meteorological model of HEC-HMS has been considered as the simplest mathematical method for modeling the amount of snowmelt runoff in many previous studies $[48,49]$.

3.2. HEC-HMS Calibration and Simulation Scenarios. In the previous section, we have identified methods that are included in HEC-HMS for runoff estimates; however, each method requires a specific number of parameters, which can be evaluated directly from the characteristics of the subbasin and channel and GIS maps [44, 46, 49], as well as recommendations from HEC-HMS developers [42].

Even with the recent suggestions in the selection of HEC-HMS parameters values, Wheater et al. [50] found that reliable estimation of model parameters through a calibration process can lead to reduced model uncertainty and improve streamflow simulations. As the literature review [51] shows, necessity calibration for the temperature index snowmelt parameters can improve the efficiency simulating snowmelt runoff. Finally, considering these issues, a total of 13 HECHMS parameters related to rainfall loss, surface runoff, baseflow, river routing, and snowmelt runoff were chosen for model calibration at a daily time step. The physical meanings of each parameter and the recommended initial ranges for the parameters are presented in Table 3.

Despite the HEC-HMS model providing the automatic optimization algorithms (Nelder-Mead simplex method and the univariate gradient search), previous numerous studies explained that these methods are still not able to deal with all parameters, which can affect the model accuracy. Hence, to overcome this problem, the HEC-HMS for GRB was calibrated manually using trial and error method to yield best fit between observed and simulated hydrographs as evidenced by Gyawali and Watkins [48]. The available observed data including daily precipitation, streamflow, air temperature, and evapotranspiration were divided into two 3-year periods (2008 to 2010 and 2011 to 2013); thus the HEC-HMS of the study area was calibrated for the first three years and then was further validated for the last three years.

Most importantly, Jiang et al. [52] highlighted that the streamflow simulation results of different precipitation inputs in both spatiotemporal resolutions and accuracy could be somewhat similar through model calibration with each of the input data. As a consequence, in the present study, to investigate the effect of the four satellite precipitation products on streamflow simulations, we performed the proposed calibration scheme by creating two simulation scenarios. In the first scenario, the HEC-HMS model was calibrated and validated using gauged precipitation datasets, and then the model was run again using forcing inputs from the four satellite-driven precipitation products with unaltered calibrated parameter values of gauge observations. In the second scenario, the four satellite precipitation products were used as the forcing inputs to recalibrate the HEC-HMS model and then for validation as in the same periods of scenario I. It is important to note that the first scenario is usually conducted because it provides better comparison of the streamflow simulation accuracy between the satellite products and the gauged precipitation observations, whereas the second scenario is aimed at examining the influence of satellite precipitation datasets uncertainty on streamflow simulations as reported in $[11,14]$.

3.3. Statistical Criteria of Performance Evaluation. In our research, for checking the accuracy of four satellite-based precipitation estimates, three different verification methods were adopted, which are detailed below. 
TABLE 3: Calibration parameters for hydrologic simulation of HEC-HMS model.

\begin{tabular}{|c|c|c|c|c|}
\hline Parameters & Physical meaning & Lower bound & Upper bound & Model component \\
\hline$I_{d}$ & Initial deficit, $\mathrm{mm}$ & 0 & 100 & Precipitation excess \\
\hline$M_{d}$ & Maximum deficit, $\mathrm{mm}$ & 0 & 250 & \\
\hline$C_{r}$ & Constant rate, $\mathrm{mm} / \mathrm{hr}$ & 0 & 150 & \\
\hline$T_{c}$ & Time of concentration, $\mathrm{hr}$ & 24 & 72 & Surface flow \\
\hline$S_{c}$ & Storage coefficient, $\mathrm{hr}$ & 10 & 100 & \\
\hline$R_{c}$ & Recession constant, dimensionless & 0.50 & 1 & Subsurface flow \\
\hline$R_{p}$ & Ratio to peak, dimensionless & 0 & 1 & \\
\hline K & Muskingum travel time, hr & 24 & 150 & Reaches flow \\
\hline$X$ & Muskingum weighting factor, dimensionless & 0.01 & 0.2 & \\
\hline$W_{\mathrm{mr}}$ & Wet melt rate, $\mathrm{mm} /{ }^{\circ} \mathrm{c}$-day & 0 & 10 & Snowmelt flow \\
\hline$R_{\mathrm{mr}}$ & Rain rate limit, $\mathrm{mm} /$ day & 0 & 600 & \\
\hline $\mathrm{ATI}_{\mathrm{mr}}$ & Melt rate antecedent temperature index coefficient, dimensionless & 0 & 1 & \\
\hline $\mathrm{ATI}_{\mathrm{cr}}$ & Cold content antecedent temperature index coefficient, dimensionless & 0 & 1 & \\
\hline
\end{tabular}

3.3.1. Continuous Statistical Indices. To qualitatively verify the satellite precipitation products in comparison with gauged precipitation observations, the following validation statistical indices were used: the mean error (ME), mean absolute error (MAE), correlation coefficient (CC), rootmean-square error (RMSE), and relative bias $\left(R_{\text {bias }}\right)$. These are calculated, as shown in (1), (2), (3), (4), and (5), respectively:

$$
\begin{aligned}
\mathrm{ME} & =\frac{\sum_{i=1}^{n}\left(P_{\mathrm{est}, i}-P_{\mathrm{obs}, i}\right)}{n} \\
\mathrm{MAE} & =\frac{\sum_{i=1}^{n}\left|\left(P_{\mathrm{est}, i}-P_{\mathrm{obs}, i}\right)\right|}{n} \\
\mathrm{CC} & =\frac{\sum_{i}^{n}\left(P_{\mathrm{obs}, i}-\bar{P}_{\mathrm{obs}, i}\right)\left(P_{\mathrm{est}, i}-\bar{P}_{\mathrm{est}, i}\right)}{\sqrt{\sum_{i}^{n}\left(P_{\mathrm{obs}, i}-\bar{P}_{\mathrm{obs}, i}\right)^{2}} \sqrt{\sum_{i}^{n}\left(P_{\mathrm{est}, i}-\bar{P}_{\mathrm{est}, i}\right)^{2}}} \\
\mathrm{RMSE} & =\sqrt{\frac{\sum_{i=1}^{n}\left(P_{\mathrm{est}, i}-P_{\mathrm{obs}, i}\right)^{2}}{n}} \\
R_{\mathrm{bias}} & =\frac{\sum_{i=1}^{n} P_{\mathrm{est}, i}-\sum_{i=1}^{n} P_{\mathrm{obs}, i}}{\sum_{i=1}^{n} P_{\mathrm{obs}, i}} \times 100,
\end{aligned}
$$

where $P_{\text {obs }, i}$ and $\bar{P}_{\text {obs }, i}$ are, respectively, the individual and averaged observed precipitation provided by ground-based data, $P_{\text {est }, i}$ and $\bar{P}_{\text {est }, i}$ are, respectively, the individual and averaged estimated precipitation provided by satellite-derived products, and $n$ is the total number of time steps. The observed and estimated precipitation are considered fully consistent without uncertainty of satellite rainfall products if the values of ME, MAE, RMSE, and BIAS $=0$ and value of CC $=1$. More detailed information about the continuous indices are referenced in [53].

3.3.2. Categorical Statistical Indices. To better analyze the capacity of the satellite-based precipitation estimates in detecting the observed occurrence of precipitation at different precipitation thresholds, the authors adopted four categorical indices, as proposed by Wilks [54] and followed by various authors $[27,55,56]$, depending on $2 \times 2$ contingency table including the frequency bias index (FBI), probability of detection (POD), false-alarm rate (FAR), and critical success index (CSI). These are calculated as in (6), (7), (8), and (9), respectively:

$$
\begin{aligned}
\mathrm{FBI} & =\frac{H+F}{H+M} \\
\mathrm{POD} & =\frac{H}{H+M} \\
\mathrm{FAR} & =\frac{F}{H+F} \\
\mathrm{CSI} & =\frac{H}{H+M+F},
\end{aligned}
$$

where $H, M$, and $F$ represent the total number of hits (observed precipitation correctly detected), misses (observed precipitation not detected), and false alarms (precipitation detected but not observed), respectively. The computed values of 1 for FBI, POD, and CSI indicate better accuracy in representation, while 0 is the optimal value of FAR. The explanations of these categorical criteria and other details are well described in [54-56].

3.3.3. Hydrologic Model Evaluation Indices. In order to assess the impact of satellite precipitation products on streamflow simulation over the GRB by the HEC-HMS model, four statistical criteria were selected to measure the goodness-offit of HEC-HMS model simulations, which are the NashSutcliffe Efficiency $\left(E_{\mathrm{NS}}\right)$, determination coefficient $\left(R^{2}\right)$, and index of agreement $(D)$ and the relative bias ratio. The relevant equations (10), (11), (12) and (13) are, respectively, given as follows:

$$
E_{\mathrm{NS}}=1-\frac{\sum_{i=1}^{n}\left(Q_{\mathrm{obs}, i}-Q_{\mathrm{sim}, i}\right)^{2}}{\sum_{i=1}^{n}\left(Q_{\mathrm{obs}, i}-\bar{Q}_{\mathrm{obs}, i}\right)^{2}}
$$



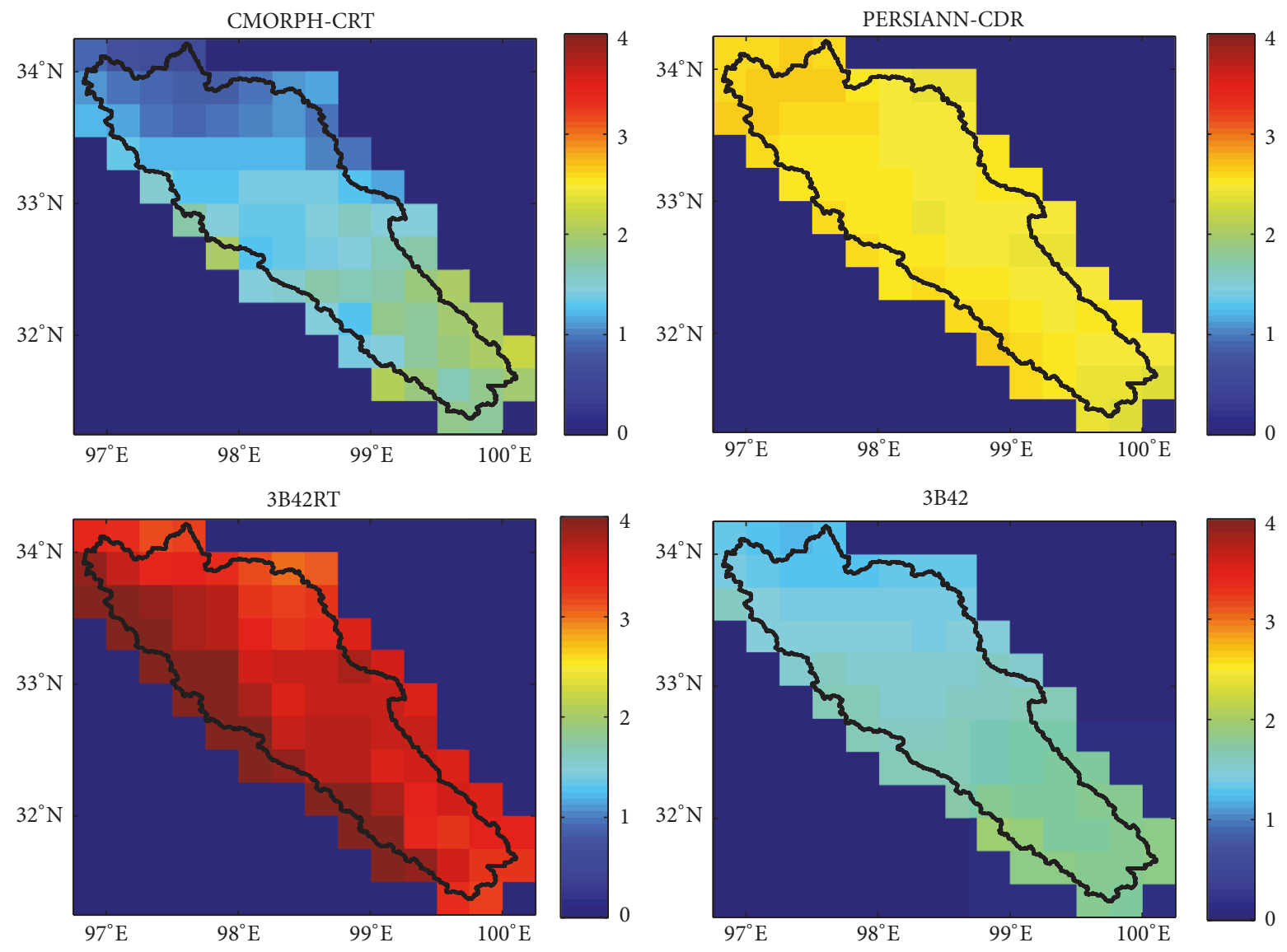

FIGURE 3: Maps of six-year daily average precipitation $\left(\mathrm{mm} \mathrm{day}^{-1}\right)$ at $0.25^{\circ}$ resolution derived from CMORPH-CRT, PERSIANN-CDR, 3B42RT, and 3B42 estimates over GRB during the period 2008 to 2013.

$$
\begin{aligned}
& R_{\mathrm{bias}}=\frac{\sum_{i=1}^{n} Q_{\mathrm{sim}, i}-\sum_{i=1}^{n} Q_{\mathrm{obs}, i}}{\sum_{i=1}^{n} Q_{\mathrm{obs}, i}} \times 100 \\
& R^{2} \\
& =\frac{\left[\sum_{i=1}^{n}\left(Q_{\mathrm{sim}, i}-\bar{Q}_{\mathrm{sim}, i}\right) \sum_{i=1}^{n}\left(Q_{\mathrm{obs}, i}-\bar{Q}_{\mathrm{obs}, i}\right)\right]^{2}}{\left[\sum_{i=1}^{n}\left(Q_{\mathrm{sim}, i}-\bar{Q}_{\mathrm{sim}, i}\right)^{2}\right]\left[\sum_{i=1}^{n}\left(Q_{\mathrm{obs}, i}-\bar{Q}_{\mathrm{obs}, i}\right)^{2}\right]} \\
& D=1-\frac{\sum_{i=1}^{n}\left(Q_{\mathrm{obs}, i}-Q_{\mathrm{sim}, i}\right)^{2}}{\sum_{i=1}^{n}\left(\left|Q_{\mathrm{sim}, i}-\bar{Q}_{\mathrm{obs}, i}\right|+\left|Q_{\mathrm{obs}, i}-\bar{Q}_{\mathrm{obs}, i}\right|\right)^{2}}
\end{aligned}
$$

in which $Q_{\mathrm{obs}, i}, Q_{\mathrm{sim}, i}, \overline{\mathrm{Q}}_{\mathrm{obs}, i}$, and $\bar{Q}_{\mathrm{sim}, i}$ are, respectively, the observed streamflow, the simulated streamflow, the average observed streamflow, and the average simulated streamflow at any given time step $i$, and $n$ is the total number of time steps. The best consistency between simulated and observed streamflow is judged on the basis of the indicator values of $\left(E_{\mathrm{NS}}, R^{2}\right.$, and $\left.D\right)$, which should be close to 1 , and a lower $R_{\text {bias }}$ value. The ranges of these indicators have been selected in this study according to the Moriasi et al. [53] recommendations.

\section{Results and Discussions}

4.1. Evaluation and Comparison of Satellite-Gauged Precipitation Estimates. In the following sections, we evaluate the accuracy of the satellite precipitation estimates against gauged precipitation datasets over the study region because of the negative effects of their associated uncertainties on the hydrological modeling process. The comparative analysis was conducted over 6 years (2008-2013) and seasonal daily average datasets to investigate and characterize precipitation patterns and error quantification of the four satellite products over the GRB as described below.

4.1.1. Annual Spatial Patterns Analysis of Satellite Precipitation Estimates. The spatial distribution of daily average precipitation from CMORPH-CRT, PERSIANN-CDR, 3B42RT, and $3 B 42$ for six years $(2008-2013)$ on a $0.25^{\circ}$ grid over GRB is compared and illustrated in Figure 3. Visual inspection of Figure 3 shows that the average annual precipitation ranges are between 0.7 and 2.1, 2.5 and 2.8, 3.4 and 4, and 1.1 and 2.0 for CMORPH-CRT, PERSIANN-CDR, 3B42RT, and 3B42, respectively.

It should be noted that the spatial distribution of all satellite precipitation estimates is clearly differentiated, with the precipitation intensities gradually decreasing from the western part of the basin to the eastern part. Also, the spatial variability analysis reveals that the low-altitude regions of the basin are characterized by higher spatial variability of precipitation in comparison with the high mountainous regions, which are greater than $4500 \mathrm{~m}$ in altitude. 


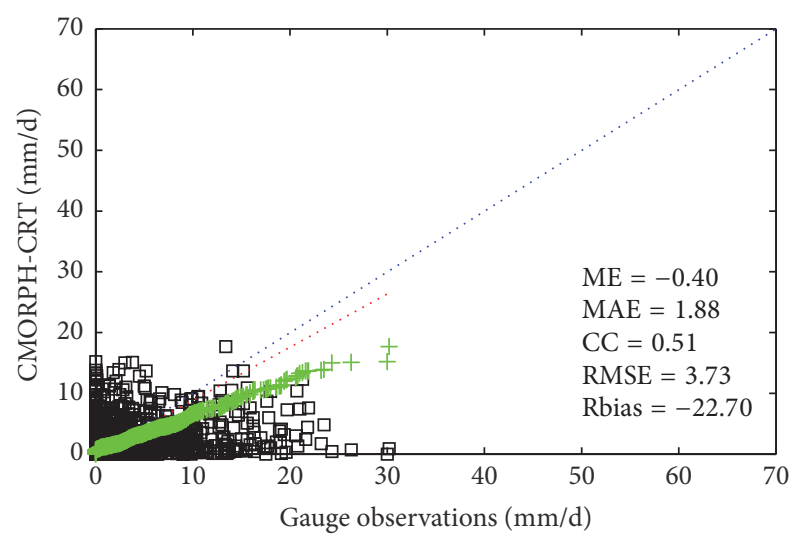

$1: 1$ line

Regression line

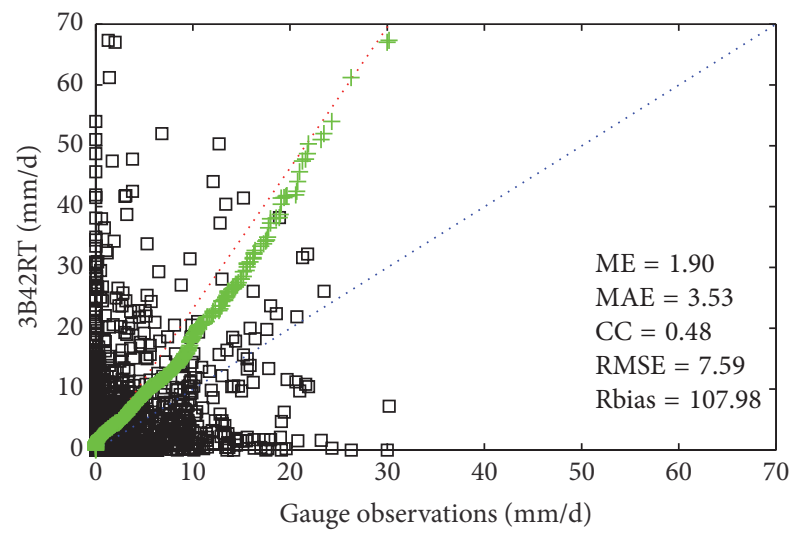

$1: 1$ line

Regression line

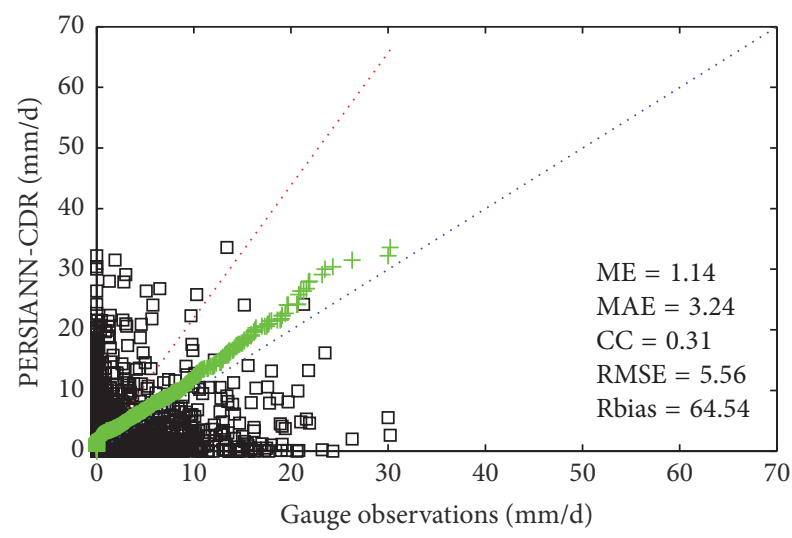

$1: 1$ line

Regression line

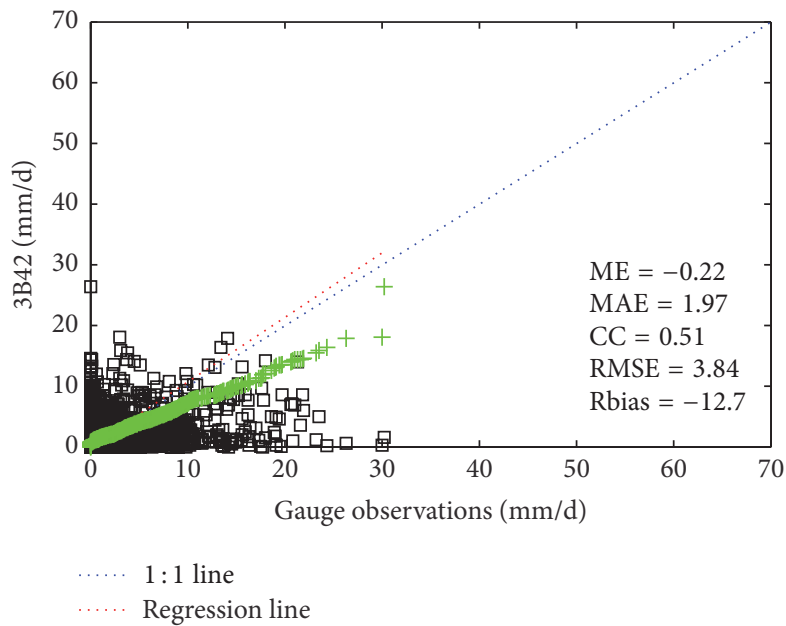

FIGURE 4: Q-Q plots (green) and scatterplots (black) of basin averaged precipitation from gauge observations versus satellite-based estimates during the period 2008 to 2013.

Despite the fact that the precipitation amount is noticeably lower with CMORPH-CRT, it is noted that the differences of spatial precipitation distribution patterns between CMORPH-CRT and 3B42 are relatively small, as both of them showed overestimation and underestimation precipitation amounts at the lower and upper regions of the basin, respectively. The highest precipitation amount was observed for 3B42RT, while the lowest spatial variability of precipitation was found for PERSIANN-CDR. On the whole, the precipitation patterns derived by CMORPH-CRT and $3 \mathrm{~B} 42$ are somewhat more visually compatible than those retrieved from PERSIANN-CDR and 3B42RT.

4.1.2. Annual Intercomparison of Satellite-Gauged Precipitation Datasets. The Quantile-Quantile (Q-Q) plot technique and scatterplots were adopted to illustrate more insight into the nature of the differences between the four satellites (CMORPH-CRT, PERSIANN-CDR, 3B42RT, and 3B42) and the gauged precipitation datasets for the total precipitation from 2008 to 2013 over the GRB (Figure 4). When looking at Figure 4, the Q-Q plots analysis shows that the daily precipitation amounts obtained by satellite and gauged datasets are significantly different. As shown, the differences in daily average precipitation estimates between satellite and gauged datasets become larger as the precipitation amount increases. Additionally, PERSSIANN-CDR and 3B42RT have the highest daily average precipitation estimates over the GRB compared with those obtained by the gauged observations of CMORPH-CRT and 3B42. However, at the same time, the precipitation estimates of CMORPH-CRT and 3B42 are lower than the gauged observations. Overall, the CMORPH-CRT, PERSIANNN-CDR, and 3B42 provide the best agreement with gauged observations than the precipitation estimates from 3B42RT, except some noteworthy biases in the middle and upper portions of the distributions.

In addition, the five criteria, ME, MAE, RMSE, CC, and $R_{\text {bias }}$, have been also included in Figure 4 and calculated based on the daily basin averaged precipitation of satellite and gauged datasets during the period 2008-2013. Generally, the best values of $\mathrm{MAE}=1.88$ and $\mathrm{RMSE}=3.73$ are found for CMORPH-CRT, whereas 3B42 observed the best value of $\mathrm{ME}=-0.22$, with a similar $\mathrm{CC}=0.51$ value for both products. In contrast, the 3B42RT shows the poorest values of $\mathrm{ME}=1.90, \mathrm{MAE}=3.53$, and $\mathrm{RMSE}=7.59$, except for 

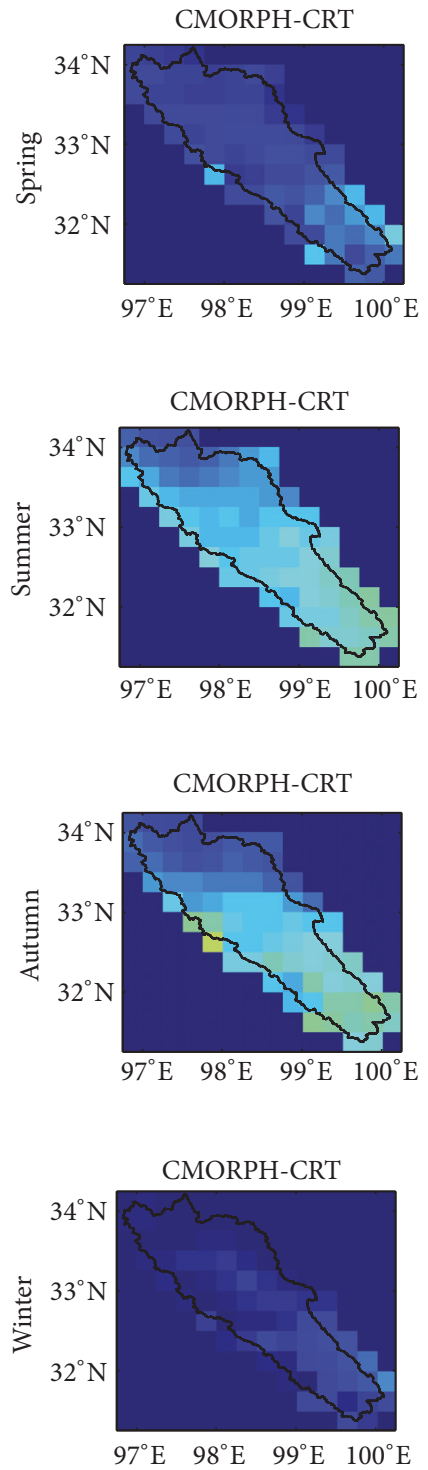

PERSIANN-CDR

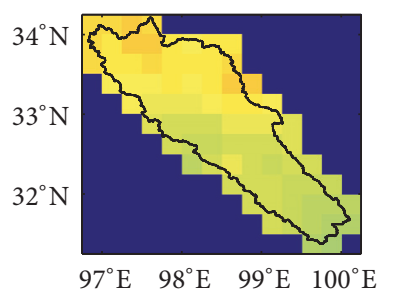

3B $42 \mathrm{RT}$

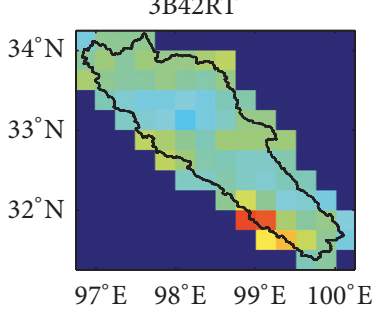

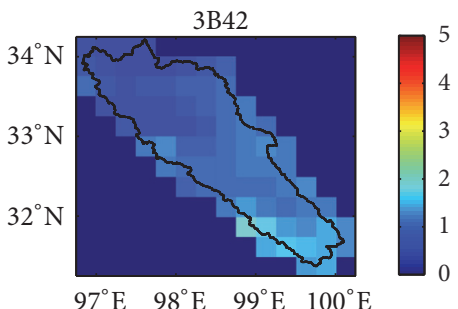

$97^{\circ} \mathrm{E} \quad 98^{\circ} \mathrm{E} \quad 99^{\circ} \mathrm{E} \quad 100^{\circ} \mathrm{E}$

(a)
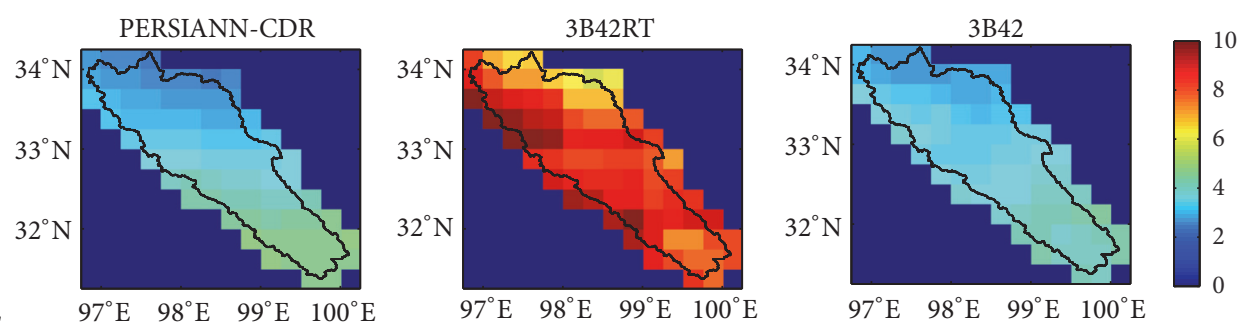

(b)
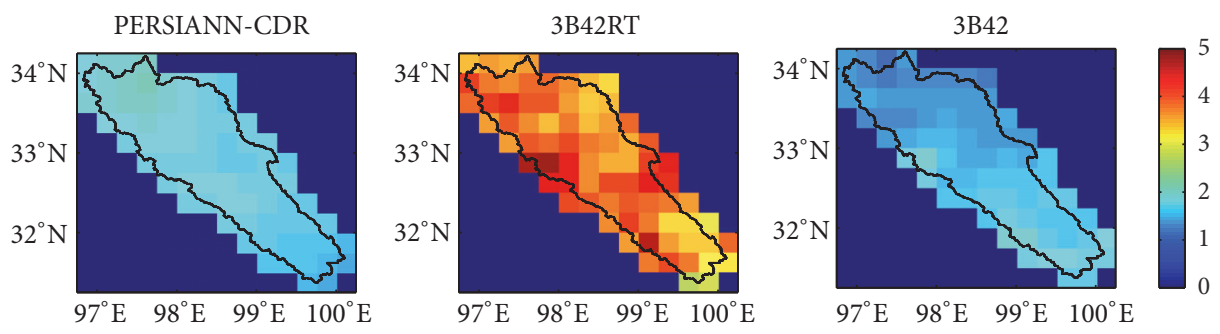

(c)

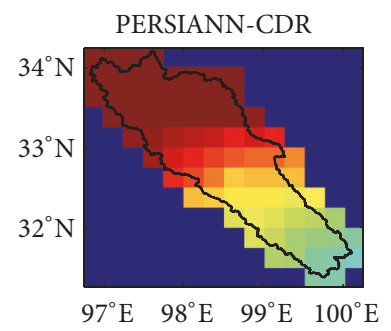

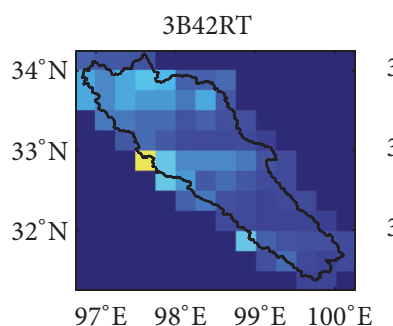

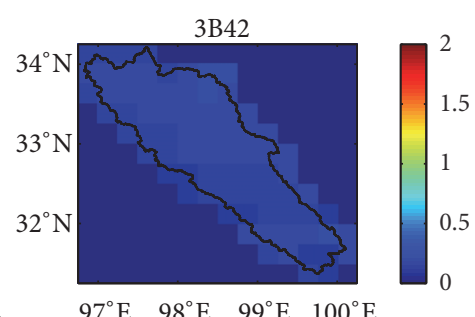

$97^{\circ} \mathrm{E} \quad 98^{\circ} \mathrm{E} \quad 99^{\circ} \mathrm{E} \quad 100^{\circ} \mathrm{E}$

(d)

FIGURE 5: Maps of seasonal daily average precipitation $\left(\mathrm{mm} \mathrm{day}^{-1}\right)$ at $0.25^{\circ}$ resolution derived from CMORPH-CRT, PERSIANN-CDR, 3B42RT, and 3B42 estimates for spring, summer, autumn, and winter (from (a) to (d)) over GRB during the period 2008 to 2013.

$\mathrm{CC}=0.31$ from PERSIANN-CDR. These values indicate that both CMORPH-CRT and 3B42 have better agreements with gauged datasets in this area. As seen from the results of statistical analysis in Figure 4, the 3B42RT exhibits the largest positive percentage of biases which are relatively larger than PERSIANN-CDR. However, the underestimation of the precipitation rates occurs only with CMORPH-CRT and 3B42, which leads to significantly lower biases of PERSIANNCDR and 3B42RT. Although 3B42RT strongly overestimates precipitation by 107.98, 3B42 slightly underestimates it (less than 3.84). The results suggest that both CMORPH-CRT and 3B42 have more reasonable performance than 3B42RT and PERSIANN-CDR in terms of all criteria over GRB region.

4.1.3. Seasonal Spatial Patterns Analysis of Satellite Precipitation Estimates. Figure 5 shows the seasonal spatial patterns of daily average CMORPH-CRT, PERSIANN-CDR, 3B42RT, and $3 \mathrm{~B} 42$ precipitation estimates in four seasons, spring (March to May), summer (June to August), autumn (September to November), and winter (December to February), for the period January 2008-December 2013. Clearly, the spatial patterns of CMORPH-CRT and 3B42 precipitation estimates are significantly identical, as well as the precipitation intensity increasing from the northeast to the southwest over the GRB, which is especially consistent with spatial patterns of precipitation regardless of the season. In contrast, the spatial patterns of precipitation across the four seasons in PERSIANN-CDR and 3B42RT are very distinct with different intensity distributions of precipitation.

On the other hand, both 3B42RT and PERSIANN-CDR showed the highest volume of precipitation through the four seasons in comparison with 3B42 and CMORPH-CDR. 
In addition, the largest values of precipitation amounts for CMORPH-CRT, 3B42RT, and 3B42 were mainly observed during the wet period (summer and autumn), while PERSIANN-CDR recorded highest values during the dry period (winter and spring). The important feature from Figure 5 is that the seasonal spatial variability for CMORPHCRT, PERSIANN-CDR, and 3B42 gradually increases from northern parts to the southern parts of the basin. However, this relationship is not clear for 3B42RT, where the spatial variability of precipitation is more scattered and the highest along the GRB.

4.1.4. Seasonal Intercomparison of Satellite-Gauged Precipitation Datasets. The seasonal differences of precipitation estimates derived from the CMORPH-CRT, PERSIANNCDR, 3B42RT, and 3B42 against gauged observations were analyzed using Q-Q plots and scatter plots (Figure 6).

An inspection of Figure 6 reveals that CMORPH-CRT and 3B42 exhibit the lowest average precipitation estimates over the GRB compared to gauged observations when compared to others regardless of the season. The precipitation estimates from 3B42RT are higher than gauged observations, except during the winter, which are relatively closer to gauged observations in the estimation of high precipitation. The percent agreement between satellite and gauged datasets increases for the wet seasons (summer and autumn) and decreases for the other seasons. However, it is notable that the differences between precipitation estimates from satellite and gauged datasets become larger during the winter, especially for the PERSIANN-CDR product. In addition, the biases in the estimation of the precipitation amount are much higher in the middle parts of the probability distributions, with relatively medium daily average precipitation events regardless of seasonal changes, except 3B42RT which showed higher medium and high precipitation biases in every season.

Besides Q-Q plots and scatterplots analysis, the five criteria ME, MAE, CC, RMSE, and Rbias were used to quantify a comparison of satellite and gauge precipitation datasets in four seasons, as shown in Figure 6. It is evident that the seasonal fluctuations have noteworthy influence on the accuracy of the satellite estimates. Although there is a slight difference between CMORPH-CRT and 3B42, PERSIANNCRT and 3B42RT show remarkable dissimilarity in every season. The worst performance is found through PERSIANN$\mathrm{CDR}$ and 3B42RT with the lowest $\mathrm{CC}$ and the largest ME, MAE, RMSE, and Rbias (the highest Rbias being 1635.15 and 246.63, resp.), especially during the winter, which can be attributed to substantial overestimation of precipitation.

In contrast, CMORPH-CRT and 3B42 perform better and are comparable among the other products, based on increased CC and reduced ME, MAE, RMSE, and Rbias. Broadly, CMORPH-CRT has the highest accuracy in terms of MAE and RMSE, whereas 3B42 outperforms others in terms of $\mathrm{ME}$ and Rbias in every season. The $\mathrm{CC}$ values of all estimates are higher in the wet period and reach 0.54 and 0.65 for summer and autumn, respectively, with 3B42; however, CMORPH-CRT and 3B42 have the highest correlations with gauge observations compared to others. Additionally, it is obviously seen that all products performed worst in winter with the lowest CC value of PERSIANNCDR (-0.01), followed by 3B42RT (0.03), then CMORPHCDR (0.05), and finally 3B42 (0.1). These are analogous to the findings by Wang et al. [55], who pointed out that the CMORPH-CRT, 3B42RT, and 3B42 cannot perform well in the winter season over basins of the Southeast Tibetan Plateau.

\subsubsection{Evaluation of Satellite-Gauged Precipitation Datasets} at Different Thresholds. The intensity distributions of the daily precipitation at different precipitation thresholds along with their relative contributions to the total precipitation are plotted in Figure 7. The figure clearly shows that there are remarkable differences between satellite and gauged datasets for precipitation occurrence under different precipitation classes, which begins to decrease when precipitation intensity ranges are greater than $5 \mathrm{~mm} /$ day, except for 3B42RT in the high rainfall class ( $>20 \mathrm{~mm} /$ day). The largest intensity occurrence of gauge data is nonrainy days, which occur approximately $60 \%$ of the total days, but for satellite datasets, the largest precipitation occurrence is $0<$ rainfall $\leq 1 \mathrm{~mm}$ /day estimated by CMORPH-CRT, 3B42RT, and 3B42, accounting for $35-50 \%$ of the total precipitation, while the $1<$ rainfall $\leq$ $5 \mathrm{~mm} /$ day is the largest class for the PERSIANN-CDR data, occurring about $35 \%$ of the total days. While CMORPHCRT and 3B42 tend to underestimate the occurrences of the precipitation class ranges of $5<$ rainfall $\leq 20 \mathrm{~mm} /$ day and rainfall $>20 \mathrm{~mm} /$ day, PERSIANN-CDR and 3B42RT overestimate the occurrence of all precipitation classes except nonrainy days. In addition, the precipitation class of $1<$ rainfall $\leq 5 \mathrm{~mm} /$ day has the largest precipitation contribution rates for CMORPH-CRT, PERSIANN-CDR, and 3B42, which contributes about $30-40 \%$ of the total rainfall for all three datasets. While the dominant precipitation classes for gauge data and 3B42RT are $5<$ rainfall $\leq 10 \mathrm{~mm} /$ day and rainfall $>20 \mathrm{~mm} /$ day, respectively, both classes contribute more than $35 \%$ of the total precipitation amounts for 3B42RT and gauge datasets.

The occurrences of the first two classes, that is, nonrainy and light precipitation classes of $0<$ rainfall $\leq 1 \mathrm{~mm} /$ day from all satellite datasets, are smaller than the gauge observations (maximal about 68\% for CMORPH-CRT data), although their contributions to the total rainfall are larger than those from gauge data (maximal 14\% for CMORPHCRT data). The number of occurrences of recorded middle rainfall class range $1<$ rainfall $\leq 15 \mathrm{~mm} /$ day from all satellite datasets is larger than that of gauge data, accounting for as high as $30-50 \%$ of the total days. But the contribution rates are larger for CMORPH-CRT and 3B42 and smaller for PERSIANN-CDR and 3B42RT than that of rain gauge rainfall. Notably, the occurrences and contribution rates for the precipitation class of $5<$ rainfall $\leq 10 \mathrm{~mm}$ /day are almost equivalent between the $3 \mathrm{~B} 42$ and gauge datasets. For high precipitation class range rainfall $>15 \mathrm{~mm}$ /day, CMORPHCRT and 3B42 slightly underestimate the occurrence by $0.13 \%$ and $0.27 \%$ of total days, respectively, and their precipitation contribution rates are dramatically lower than those of PERSIANN-CDR, 3B42RT, and gauged data. For PERSIANN-CDR and 3B42RT, the occurrences are both 

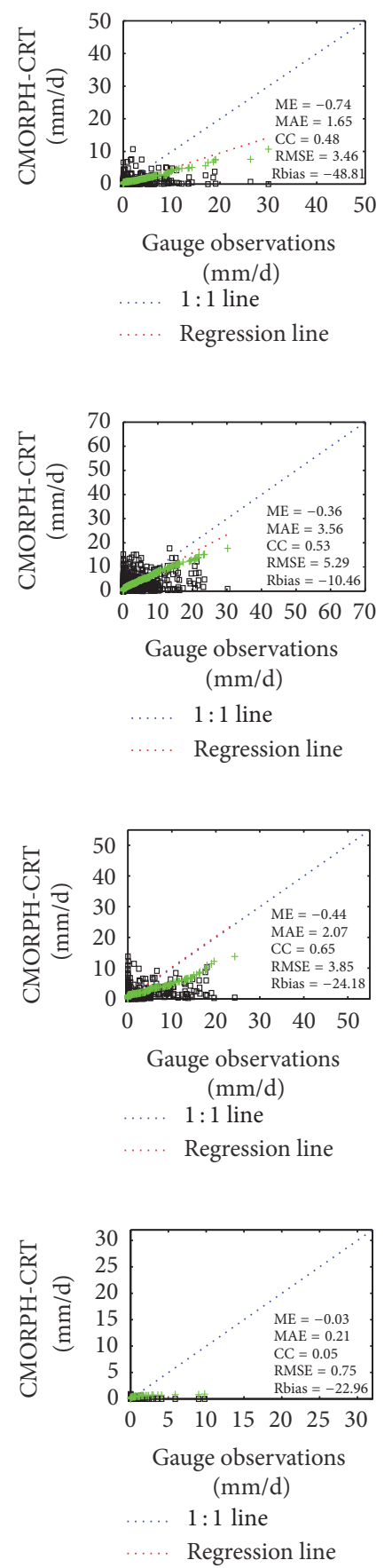

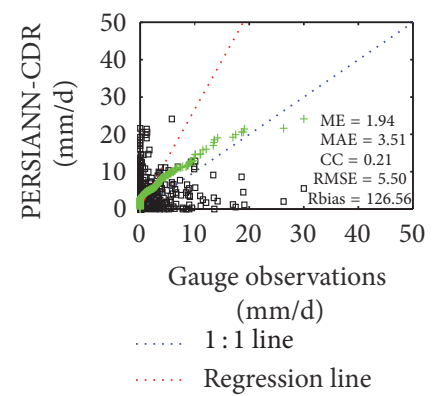

(a)

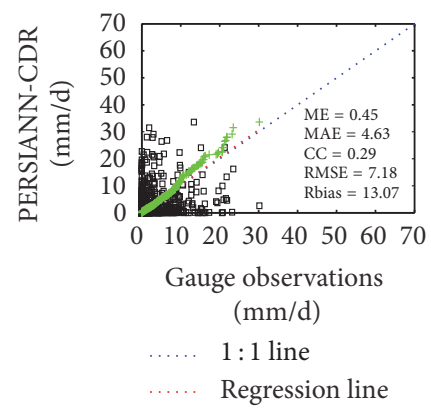

(b)

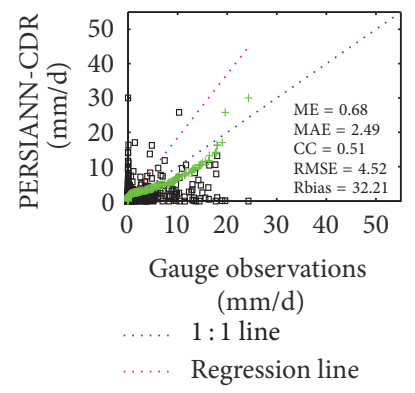

(c)

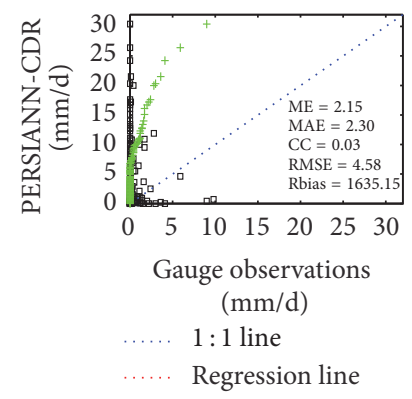

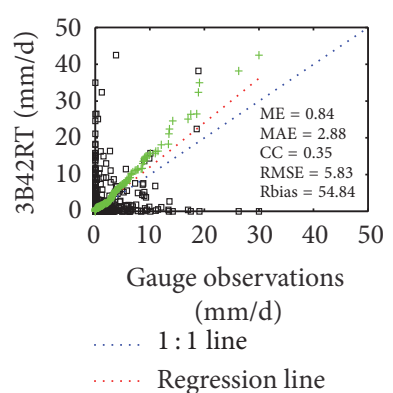
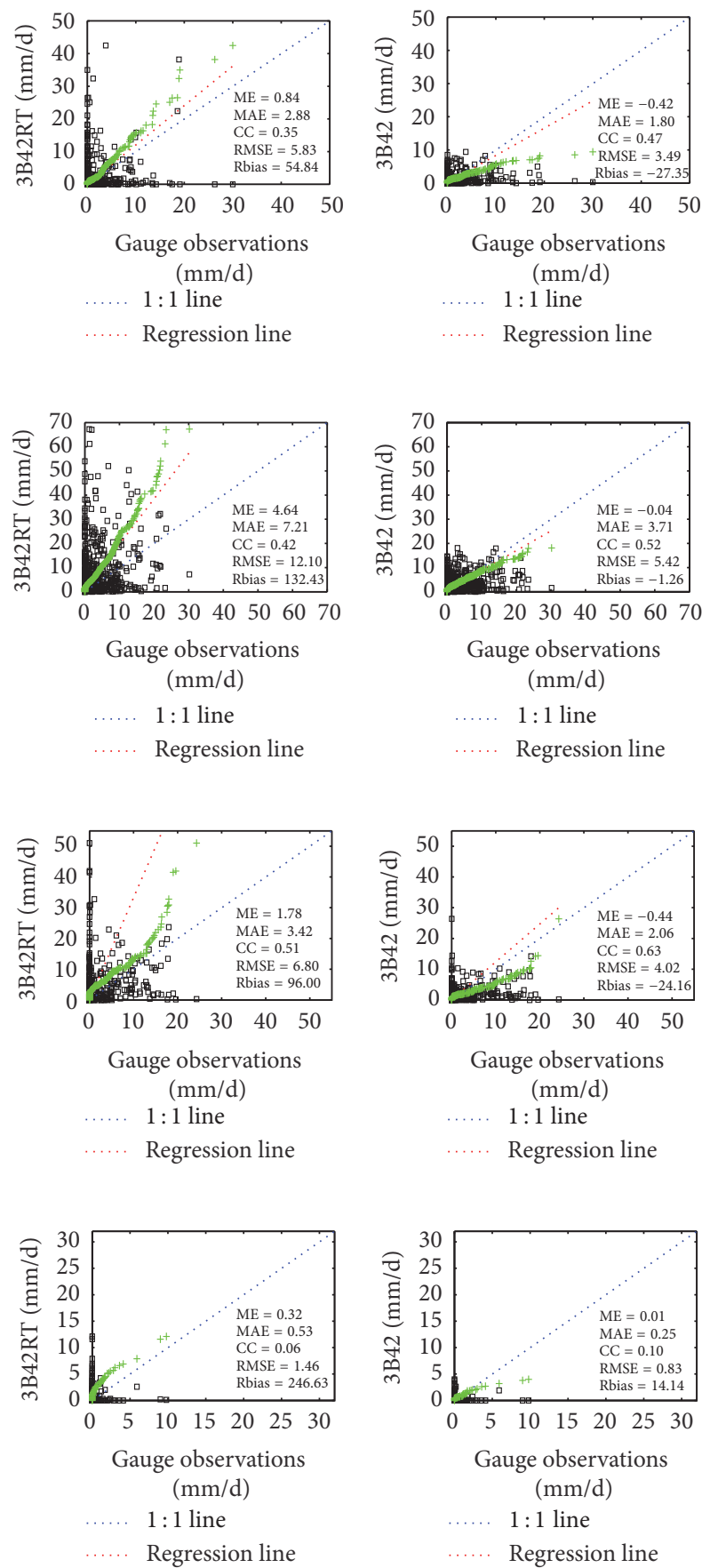

(d)

FIGURE 6: Quantil-Quantil (green) plots and scatterplots (black) of basin averaged precipitation from gauge observations versus satellite-based estimates for (a) spring, (b) summer, (c) autumn, and (d) winter during the period 2008 to 2013.

below $6 \%$ of the total days, while the contribution rates to the total rainfall amounts are as high as 20 and $40 \%$, respectively. Overall, when comparing with gauge data for light and middle class range rainfall, both the occurrences and contribution rates of CMORPH-CRT and 3B42 have better agreement with gauge data than PERSIANN-CRT and 3B42RT.

In this study, the detection analysis of precipitation events was also performed to examine the ability of CMORPH-CRT,
PERSIANN-CDR, 3B42RT, and $3 \mathrm{~B} 42$ to make estimates over the GRB using contingency statistics (FBI, POD, FAR, and CSI) at different precipitation thresholds of $1 \mathrm{~mm} /$ day, $5 \mathrm{~mm} /$ day, $10 \mathrm{~mm} /$ day, $15 \mathrm{~mm} /$ day, and $20 \mathrm{~mm}$ /day (Figure 8 ). It should be noted that all index values of CMORPH-CRT and 3B42 are comparable to each other with exception of the precipitation threshold value equal to $1 \mathrm{~mm} /$ day, while index values for PERSIANN-CDR and 3B42RT show relatively high variance. 


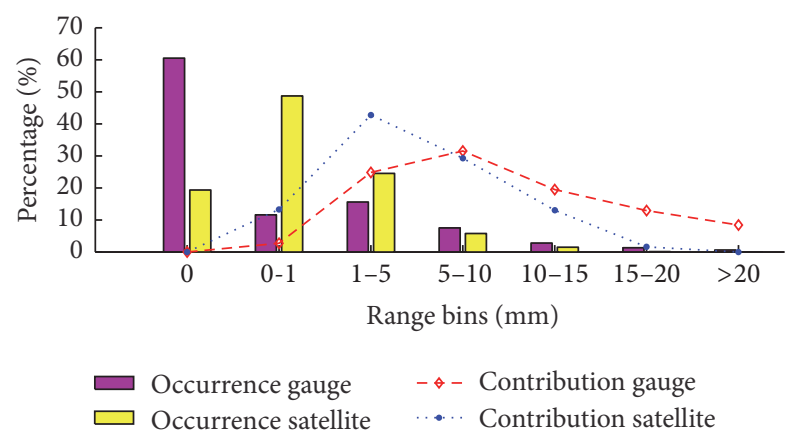

(a) Gauge versus CMORPH-CRT

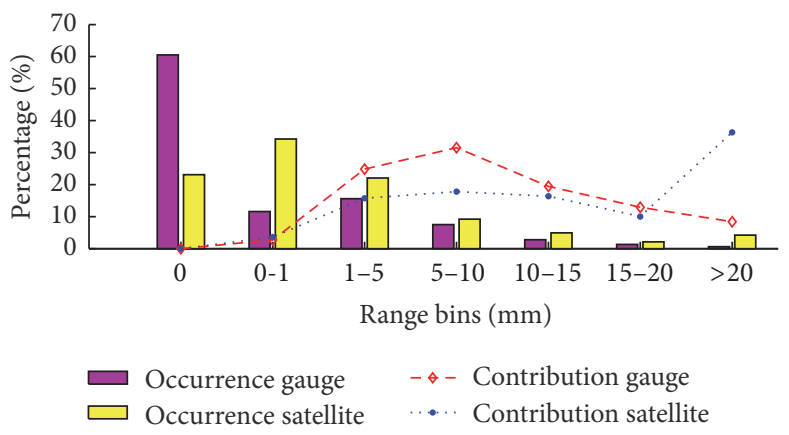

(c) Gauge versus 3B42RT

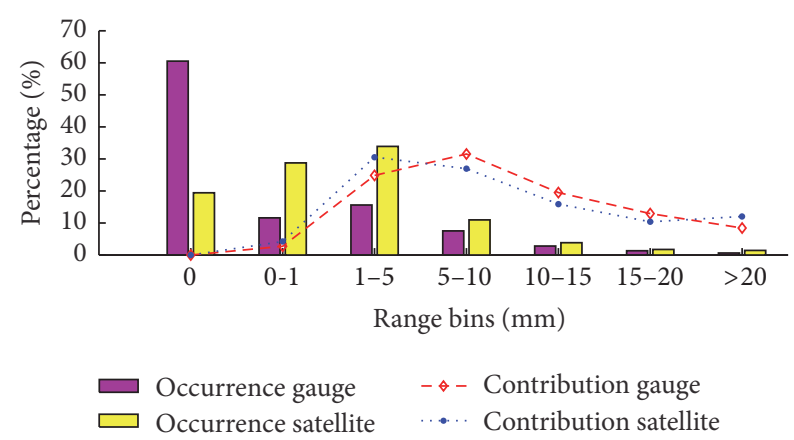

(b) Gauge versus PERSIANN-CDR

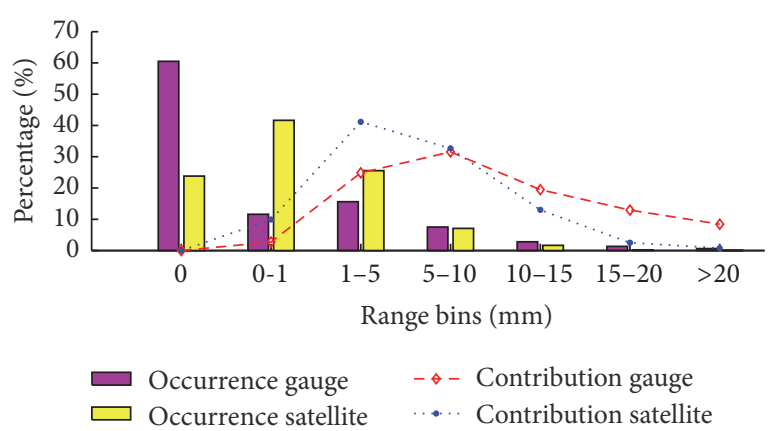

(d) Gauge versus 3B42

FIGURE 7: The intensity distribution of daily precipitation in different precipitation classes and their relative contributions to the total precipitation during the period 2008 to 2013.

However, for FBI, both CMORPH-CRT and 3B42 have a slight tendency to overestimate frequency of precipitation events for thresholds of $5 \mathrm{~mm} /$ day, $10 \mathrm{~mm} /$ day, $15 \mathrm{~mm} /$ day, and $20 \mathrm{~mm} /$ day, whereas PERSIANN-CDR and 3B42RT incline to underestimate precipitation events across all thresholds, especially the 3B42RT which shows the largest underestimation of precipitation frequency for all thresholds except $1 \mathrm{~mm} /$ day. On the other hand, the FBI values of PERSIANN-CDR and 3B42RT products increase with an increase in precipitation intensity, and FBI values from CMORPH-CRT and 3B42 decrease for the precipitation thresholds up to $5 \mathrm{~mm} /$ day, meaning the detection skill of satellite products is better for intense precipitation events. Overall, 3B42RT shows the lowest skill in capturing the magnitude of precipitation events.

It evident that all satellite products exhibit poor scores for the precipitation threshold of $1 \mathrm{~mm} /$ day, exhibiting lower POD and CSI and higher FAR. Despite the fact that the POD and CSI scores of CMORPH-CRT are larger than the other products, it seems to have relatively equivalent performance with 3B42 in all precipitation thresholds. This implies that the algorithms of both CMORPH-CRT and 3B42 satellite products not only are more effective but also incur a more positive effect on POD and CSI indices, compared to other precipitation products. Among all products, 3B42RT shows lower FAR scores during light and moderate precipitation, while all products yield comparable values for thresholds of $15 \mathrm{~mm} /$ day and $20 \mathrm{~mm} /$ day. This indicates that the PDF matching adopted by CMORPH-CRT does not excel on the monthly gauge adjustment scheme used in TRMM products to remove biases [56]. Compared with 3B42RT, 3B42 has somewhat more falsely alarmed precipitation events, leading to less effective and more uncertain FAR scores. Although 3B42 uses gauge corrections and histogram matching, suggesting the monthly bias adjusted method used by $3 \mathrm{~B} 42$ still needs to be improved in order to avoid the defects of FAR precipitation events which exist for the 3B42RT. Hence, PERSSIAN-CDR demonstrates worse FAR scores than CMORPH-CRT. Generally, all satellite products show improved performance with increasing precipitation thresholds, meaning an increased ability to capture the magnitude of intense precipitation events.

\subsection{Evaluation and Comparison of Streamflow Simulation} Scenarios. For examining the efficacy of the four satellites' CMORPH-CRT, PERSIANN-CDR, 3B42RT, and 3B42 precipitation estimates in simulating streamflow over GRB basin, we analyze their effects on the streamflow simulation using HEC-HMS model on daily time steps under two scenarios as detailed below.

4.2.1. Scenario I: Calibration Procedure Using Gauged Precipitation Datasets. As discussed in Methodology, gauged precipitation data was first used to drive the HEC-HMS model and optimize parameters against observed streamflow at the outlet in the GRB for the period of 1 January 2008-31 December 2010, while the period of 1 January 2011-31 December 2013 was subsequently used for model validation. The model was then forced by CMORPH-CDR, PERSIANN-CDR, 3B42RT, and 3B42 as inputs for six years (2008-2013) with model 


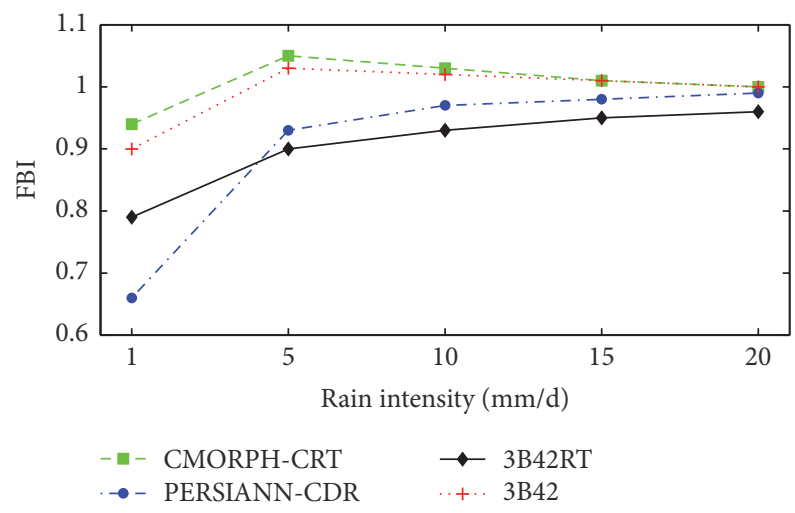

(a)

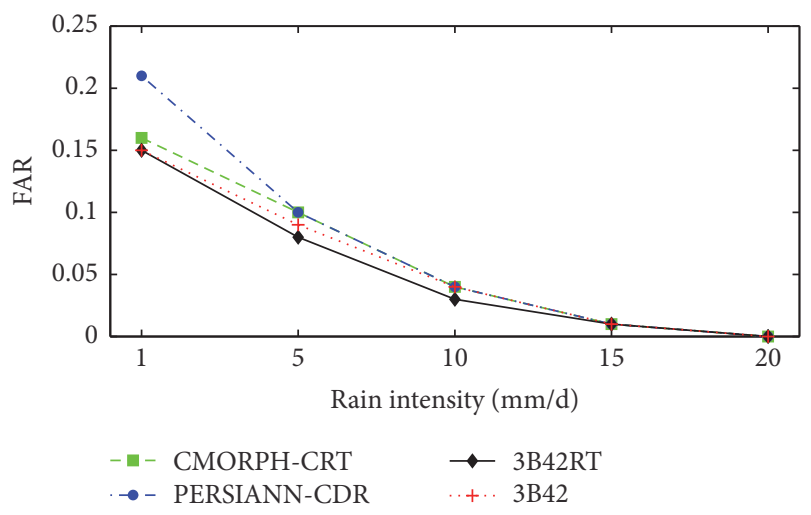

(c)

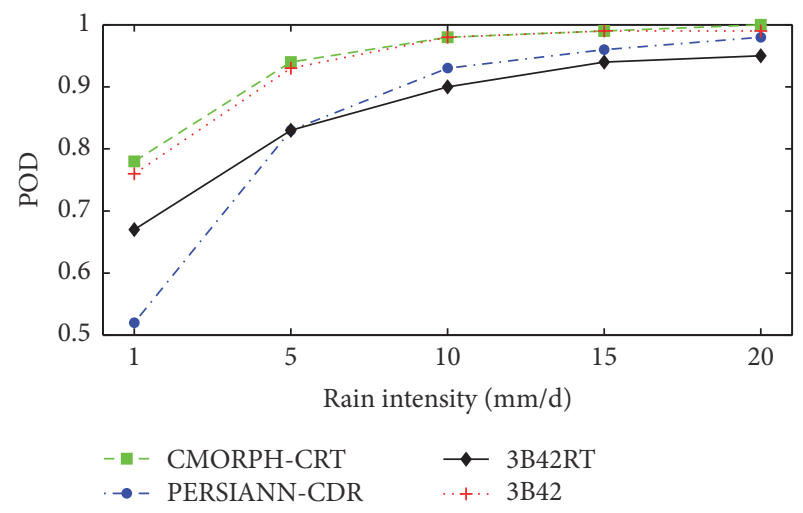

(b)

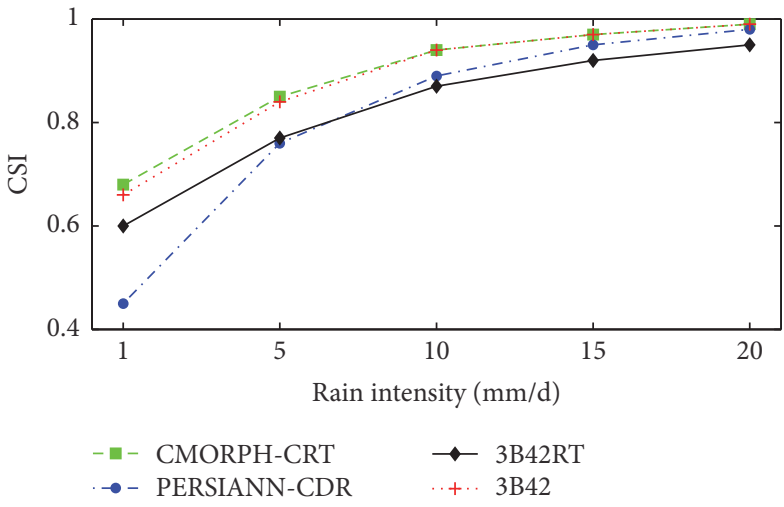

(d)

FIGURE 8: FBI (a), POD (b), FAR (c), and CSI (d) of daily average between the four satellite estimates and gauge observations over the GRB.

parameter values calibrated using gauged precipitation data in the calibration period of 2008-2010.

The hydrographs and the exceedance probability between observed daily and simulated streamflow by the HEC-HMS model, based on the four satellites and gauged precipitation datasets as precipitation forcing in the GRB during simulation time period (2008-2013), are illustrated in Figure 9. It can be seen that the simulated streamflow hydrograph obtained with the gauged precipitation dataset fits well against the observed streamflow, especially for the calibration period and the relatively low discharges during the dry seasons, as shown in Figure 9(a). It is also observed that the streamflow simulation tends to underestimate the high peak discharges in wet seasons and overestimate some values of the hydrograph recession curves for the years 2010, 2011, and 2003. Overall, the HEC-HMS model is capable of capturing the timing and magnitude of the daily observed streamflow quite well. Figure 9(f) shows that the exceedance probabilities of daily streamflows display systematic underestimation of simulated streamflows at high and low observed streamflows and overestimation at moderate streamflows; the simulations show better estimation for the calibration period than for the validation period.

Subsequently, the skill indices of HEC-HMS simulations were carried out to evaluate the model performance, and their findings for the calibration and validation periods are listed in Table 4. It can be seen from this table that the values of $E_{\mathrm{NS}}, R_{\mathrm{bias}}, R^{2}$, and $D$ are $0.80,-9.29,0.81$, and 0.94 , respectively, for the calibration period but 0.63 , $-7.67,0.67$, and 0.89 , respectively, for the validation period. These skill indices reveal that although the performance of streamflow simulation can be considered satisfactory during the validation period, it is not as good as that found for the calibration period, which exhibits good performance. It is apparent from these results that HEC-HMS model could successfully streamflow simulation at a daily time scale in the GRB, implying that the model is reliable to investigate the hydrological usefulness of satellite precipitation products in the GRB, specifically for streamflow simulation. Afterwards, the simulation streamflow hydrographs by the gauged precipitation data-forced HEC-HMS model are then compared to those forced by the four satellites' estimates of calibration and validation periods, as shown in Figures 9(b)-9(e). None of the CMORPH-CRT, PERSIANN-CDR, 3B42RT, and 3B42-driven model simulations resulted in improvements in the timing and magnitude of the observed streamflow for neither calibration nor validation periods in comparison with streamflow simulation forced by gauged precipitation data.

However, the simulations forced by 3B42RT largely overestimate peak discharges for the years 2010, 2011, and 2013 but could capture the peak discharges during other 


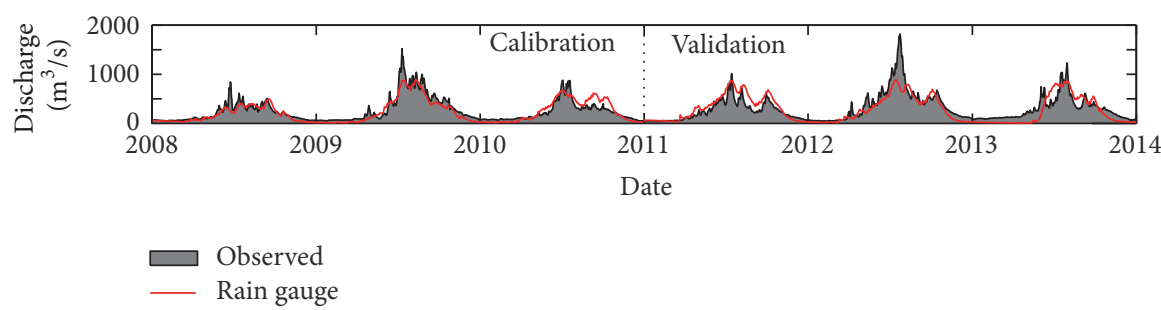

(a)

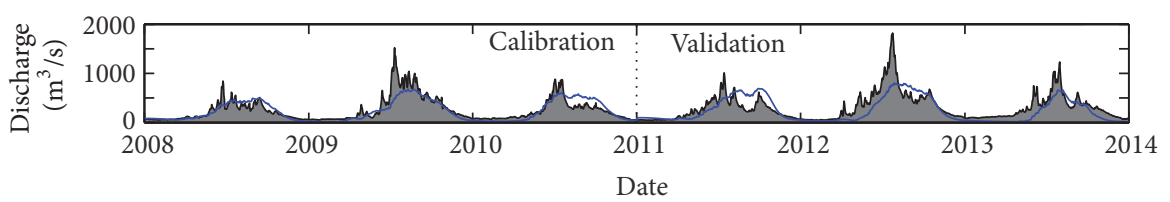

(b)

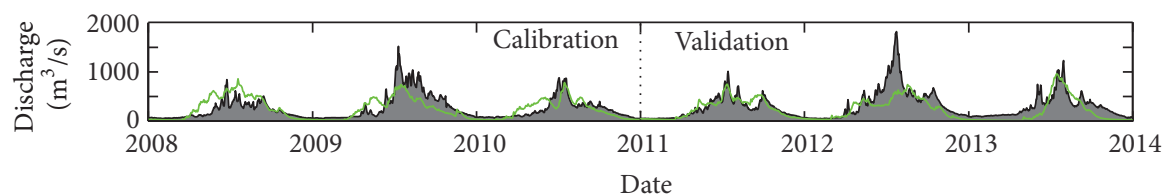

(c)

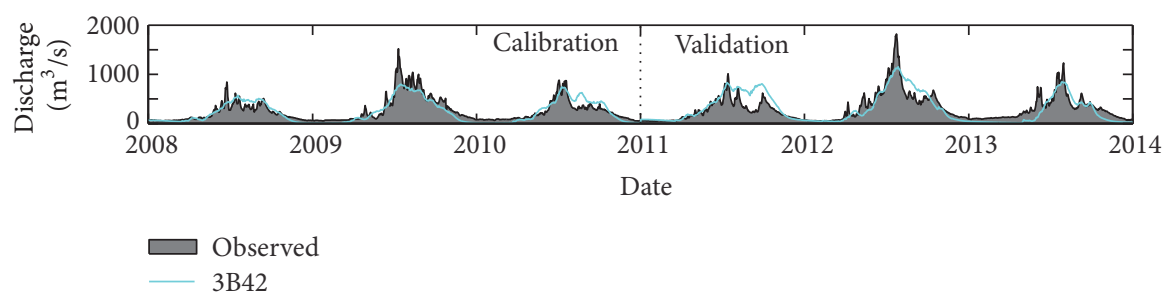

(d)

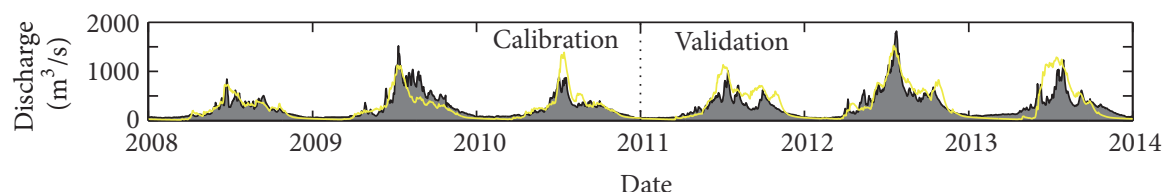

(e)

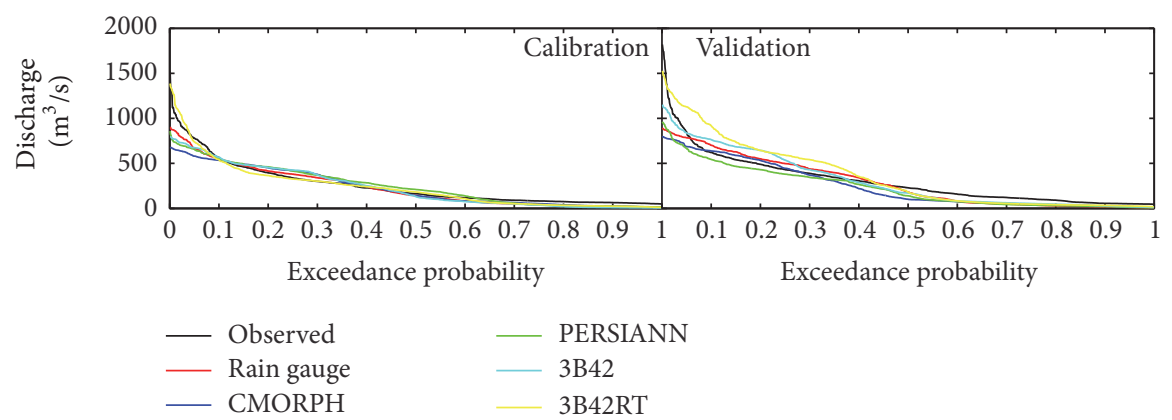

(f)

FIGURE 9: Comparison between observed daily streamflow and simulated streamflow by HEC-HMS model from (a) gauge observations, (b) CMORPH-CRT, (c) PERSIANN-CDR, (d) 3B42RT, and (e) 3B42 with benchmarked model parameter values by gauge observations; and (f) is the exceedance probabilities of daily streamflow, during the calibration (2008.1.1-2010.12.31) period and validation (2011.1.1-2013.12.31) period. 
TABLE 4: Skill indices of HEC-HMS simulations for the calibration and validation periods under scenario I.

\begin{tabular}{lccccccccc}
\hline \multirow{2}{*}{ Simulation scenario } & \multirow{2}{*}{ Datasets } & \multicolumn{4}{c}{ Calibration period } & \multicolumn{4}{c}{ Validation period } \\
& & $E_{\mathrm{NS}}$ & $R_{\text {bias }}$ & $R^{2}$ & $D$ & $E_{\mathrm{NS}}$ & $R_{\text {bias }}$ & $R^{2}$ & $D$ \\
\hline \multirow{3}{*}{ Scenario I } & Gauge & 0.80 & -9.29 & 0.81 & 0.94 & 0.63 & -7.67 & 0.74 & 0.90 \\
& CMORPH-CRT & 0.68 & -9.85 & 0.69 & 0.90 & 0.50 & -20.04 & 0.57 & 0.84 \\
& PERSIANN-CDR & 0.45 & -3.75 & 0.49 & 0.82 & 0.48 & -24.77 & 0.56 & 0.83 \\
& 3B42 & 0.77 & -8.70 & 0.78 & 0.93 & 0.64 & -1.85 & 0.70 & 0.91 \\
& 3B42RT & 0.67 & -6.26 & 0.72 & 0.91 & 0.50 & 14.56 & 0.67 & 0.89 \\
\hline
\end{tabular}

years. Conversely, PERSIANN-CDR simulations captured high peak discharges for years 2010, 2011, and 2013, while significant underestimation exists for the simulated discharges of the years 2009 and 2012. The simulations of CMORPH-CDR and 3B42 consistently underestimate the observed large peak discharges during the calibration and validation periods; however, their simulations agree well with streamflow observations and perform better in comparison to PERSIANN-CDR and 3B42RT.

From Figure 9(f), it can be clearly seen that 3B42RT shows the largest overestimation at high discharges, especially in the validation period with exceedance probabilities of up to $45 \%$. PERSIANN-CDR, on the contrary, consistently underestimates most of the observed streamflow series in the validation period but somewhat underestimates high discharges with exceedance probabilities under $1 \%$ during calibration period. Both CMORPH-CRT and 3B42 yield slight underestimation at large peak discharges with exceedance probabilities less than $10 \%$ and tend to overestimate moderate discharges. However, all four simulations exhibit significant underestimation for low discharges in the calibration and validation periods. Overall, the exceedance probabilities of simulations forced by CMORPH-CRT and 3B42 are comparatively similar to each other in the calibration and validation periods.

As it can be seen from Table 4, the model driven by gauged precipitation data indicates the best performance with the highest skill $E_{\mathrm{NS}}$ of $0.80, R^{2}$ of 0.81 , and $D$ of 0.94 in the calibration period, compared to the simulations forced by the four satellite estimates under scenario I, as expected. Nevertheless, the simulation forced by 3B42 exhibits good performance ( $E_{\mathrm{NS}}$ of $0.77, R^{2}$ of 0.78 , and $D$ of 0.93 ) and is relatively close to the gauged data of the calibration period. Additionally, in the validation period, the performance of the hydrologic model is better than those based on satellite and gauged precipitation datasets as inputs, with the highest $E_{\mathrm{NS}}$ of $0.64, R^{2}$ of 0.70 , and $D$ of 0.91 . Meanwhile, CMORPHCRT and 3B42RT derived simulations gave relatively similar performances in terms of $E_{\mathrm{NS}}$ (0.68 and 0.67), $R^{2}$ (0.69 and 0.72$)$, and $D(0.90$ and 0.91$)$ for the calibration period and $E_{\mathrm{NS}}(0.50$ and 0.50$), R^{2}$ (0.57 and 0.67), and $D(0.84$ and 0.89 ) for the validation period. It is also evident that the simulation forced by PERSIANN-CRT produces the worst overall performance among these four satellite datasets, exhibiting the smallest values for $E_{\mathrm{NS}}$ of 0.45 and $0.48, R^{2}$ of 0.49 and 0.56 , and $D$ of 0.82 and 0.83 in the calibration and validation periods, respectively. However, all simulations based on satellite and gauged precipitation datasets exhibit slight negative biases in the calibration period, specifically for $R_{\text {bias }}$ of $-3.75 \%$ corresponding with PERSSIANN-CDR, which can be considered negligible. On the other hand, in the validation period, $R_{\text {bias }}$ significantly decreases to $-7.67 \%$ and $-1.85 \%$ in simulations forced by gauge datasets and $3 \mathrm{~B} 42$, respectively, while the opposite is true for $R_{\text {bias }}$ of $-20.04 \%$, $-24.77 \%$, and $14.56 \%$ in CMORPH-CRT, PERSIANN-CDR, and 3B42RT, respectively.

The above comparison reveals that $3 \mathrm{~B} 42$ has great potential to be used alternatively for the datasets of gauged observations for hydrological simulations over mountainous watershed in the GRB, while CMORPH-CRT, PERSIANN-CDR, and 3B42RT products have limited ability for streamflow simulations and are not recommended for direct use over this region, especially the PERSIANN-CDR which is not suitable to simulate daily streamflow in this study area, though it does not show the worst results in precipitation datasets evaluation. These findings reveal that the best streamflow simulation is not necessarily required to correspond with a better satellite precipitation product, possibly due to the interaction between the precipitation datasets and streamflows. This behavior is consistent with the conclusions of Qi et al. [57].

4.2.2. Scenario II: Calibration Procedure Using Individual Satellite Datasets. In this study, scenario II is exclusively used to further analyze the effect of CMORPH-CRT, PERSIANNCDR, 3B42RT, and 3B42 products' uncertainty on streamflow simulation. The HEC-HMS model is recalibrated with each of the four satellite estimates as forcing inputs, and the calibration and validation periods of scenario I are kept unaltered within scenario II. The results are reported in Figure 10.

Figures 10(a)-10(e) demonstrate that all model simulations forced by satellite estimates match the observed hydrographs relatively well and show a greater tendency to adequately capture peak flows as compared to those of scenario I. For further illustration, in Figure 10(f) only the results from the exceedance probabilities of simulated and observed discharges are shown. It is important to note that all simulations yield slight underestimation at large peak discharges with exceedance probabilities less than $10 \%$. In contrast to scenario I, the exceedance probabilities of scenario II simulations tend to be almost similar for both the calibration and validation periods. However, Figure 10 shows that the parameter recalibration in scenario II causes an appreciable increase in enhancement in high and low streamflow simulations. 


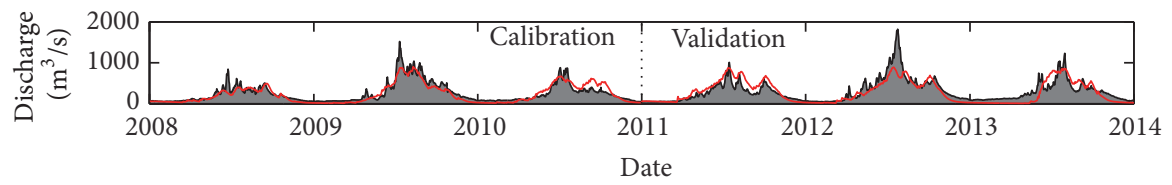

_ Rain gauge

(a)

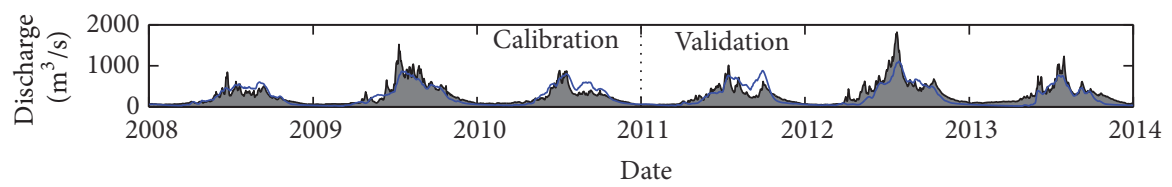

$\square$ Observed

- CMORPH

(b)

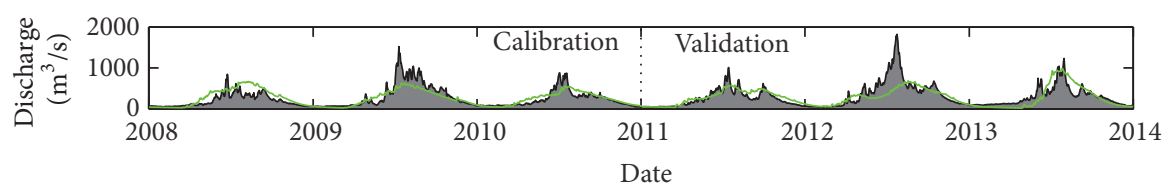

(c)

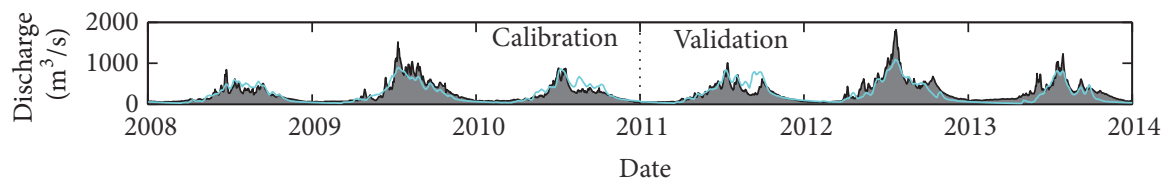

(d)

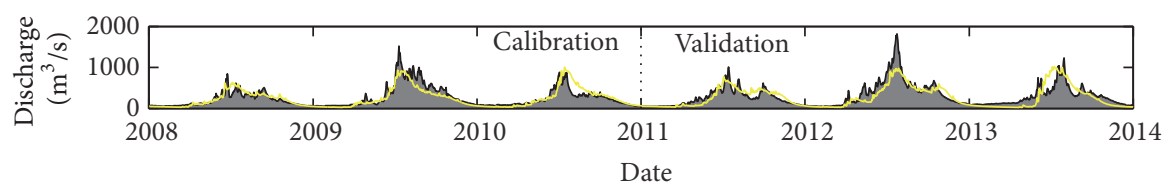

$\square$ Observed

3B42RT

(e)

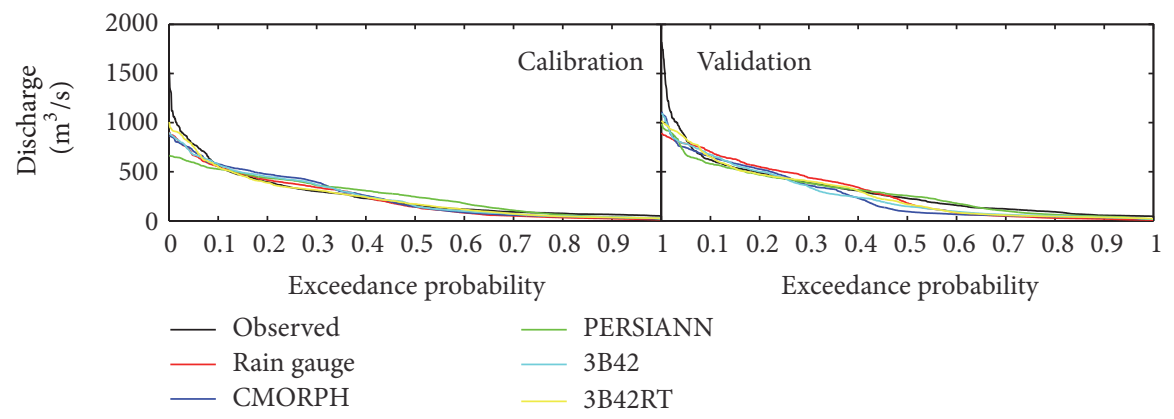

(f)

FIGURE 10: As in Figure 9, but HEC-HMS model was recalibrated and validated with each precipitation dataset as inputs during the period from 2008 to 2013. 
TABLE 5: Skill indices of HEC-HMS simulations for the calibration and validation periods under scenario II.

\begin{tabular}{|c|c|c|c|c|c|c|c|c|c|}
\hline \multirow{2}{*}{ Simulation scenario } & \multirow{2}{*}{ Datasets } & \multicolumn{4}{|c|}{ Calibration period } & \multicolumn{4}{|c|}{ Validation period } \\
\hline & & $E_{\mathrm{NS}}$ & $R_{\text {bias }}$ & $R^{2}$ & $D$ & $E_{\mathrm{NS}}$ & $R_{\text {bias }}$ & $R^{2}$ & $D$ \\
\hline \multirow{4}{*}{ Scenario II } & CMORPH-CRT & 0.77 & -2.42 & 0.78 & 0.94 & 0.69 & -17.51 & 0.73 & 0.91 \\
\hline & PERSIANN-CDR & 0.59 & 2.89 & 0.59 & 0.86 & 0.50 & -14.69 & 0.51 & 0.82 \\
\hline & $3 \mathrm{~B} 42$ & 0.80 & -2.12 & 0.80 & 0.94 & 0.71 & -7.28 & 0.74 & 0.92 \\
\hline & 3B42RT & 0.74 & -5.78 & 0.74 & 0.92 & 0.66 & -11.24 & 0.69 & 0.90 \\
\hline
\end{tabular}

Furthermore, the skill metrics of the simulation results for scenario II are summarized in Table 5. It is important to note that all satellite estimates, except PERSIANN-CDR in the validation period, show remarkably improved results with increased values of $E_{\mathrm{NS}}, R^{2}$, and $D$ and slightly decreased values of $R_{\text {bias }}$ relative to those in scenario I as explained in Table 4 . The simulation of 3B42 achieves the best performance in terms of all metrics skill when compared to other satellite products, which surpass the gauged precipitation driven simulation, especially during the validation period. Similarly for scenario I, the simulation performances of CMORPH-CRT and 3B42RT are relatively identical for both calibration and validation. At the same time the simulations of PERSIANN-CDR in scenario II show a slight improvement only during calibration period, while there is a decline in performance during the verification period as compared to scenario I. This indicates that the PERSIANN-CDR driven HEC-HMS model may still be less suitable to simulate streamflow in this study area even with the parameter recalibration in scenario II. It is obvious that all satellite precipitation forced simulations have less bias compared to scenario I, suggesting a significant decrease in the uncertainty of streamflow simulations for output satellite products under scenario II. In general, similar findings by previous studies [11, $52,56]$ reported increasing the effectiveness of hydrological simulation with input-specific recalibration.

4.2.3. Effectiveness Analysis of Calibration Procedure on Hydrologic Processes. In addition to model predictions of streamflow, the parameter recalibration results should be examined based on their capability to compensate biases in the four satellite estimates for other hydrologic processes, including snow water equivalent (SWE), base flow (BF), melt rate ATI (MR-ATI), liquid water content (LWC), and moisture deficit (MD) as shown in Figures 11 and 12.

Not surprisingly, all hydrologic components are affected by precipitation datasets as forcing inputs during dry and wet year. It is evident that PERSIANN-CDR presents larger differences in terms of SWE, MR-ATI, and LWC as compared to those of other precipitation products. Compared to scenario I, PERSIANN-CDR and 3B42RT show higher differences regarding $\mathrm{BF}$ and $\mathrm{MD}$ in dry and wet seasons, which may be due to the precipitation estimates of PERSIANN-CDR and 3B42RT being higher than those of CMORPH-CRT and 3B42. In addition, one can also see that there are slight differences in the SWE, MR-ATI, and LWC under both scenarios, especially in dry year. Unlike CMORPH-CRT and 3B42 products, there are relatively high values of SWE, MRATI, and LWC with respect to PERSIANN-CDR and 3B42RT under scenario II in dry year. While the values are relatively reduced in wet year, this causes a remarkable increase of streamflow for PERSIANN-CDR and 3B42RT than it does for CMORPH-CRT and 3B42 during the autumn and summer months. Furthermore, it can be seen that CMORPH-CRT and 3B42 for all hydrological components are nearly the same within scenario I, while noticeable differences between them can be observed in scenario II. These results reveal that scenario II tends to compensate the errors of the satellite products through an increase or decrease in hydrological components values, which may limit the ability of the model to simulate snowmelt processes over the GRB. Nevertheless, this problem is a common occurrence in hydrological communities, especially in the Alpine region, which are attributed to the unrealistic representation of the model parameters under scenario II. Based on this information, more efforts should be made to choose suitable precipitation products as forcing inputs in snowmelt processes modeling.

\section{Summary and Conclusions}

In this paper, we have made a comprehensive analysis of the applicability and reliability of the latest satellite-based precipitation datasets (CMORPH-CRT, PERSIANN-CDR, 3B42, and 3B42RT) against gauge-based datasets in the mountainous GRB of the southeast Tibetan Plateau in China. To extensively find out weaknesses and strengths of the latest four satellite products, within this context we first focused on the evaluation and comparison of different precipitation estimates and then highlighted the usefulness and suitability of each product' driven hydrological simulations with the HEC-HMS model at a daily time step. The key findings of this study can be listed as the following:

(i) Overall, the spatial patterns of CMORPH-CRT and 3B42 precipitation estimates are more similar than those retrieved from PERSIANN-CDR and 3B42RT at annual and seasonal scales. Also, the spatial variation for the four products obviously depends on the basin's elevation, and this variation decreases in the high mountainous areas with altitudes greater than $4500 \mathrm{~m}$. Apparently, 3B42RT shows more scattering and the highest spatial fluctuations, especially on the seasonal scale.

(ii) Comparing satellite and gauged-based precipitation datasets at an annual scale, both CMORPH-CRT and 3B42 demonstrate better performance than 3B42RT and PERSIANN-CDR in terms of all criteria over GRB region. In addition, CMORPH-CRT 


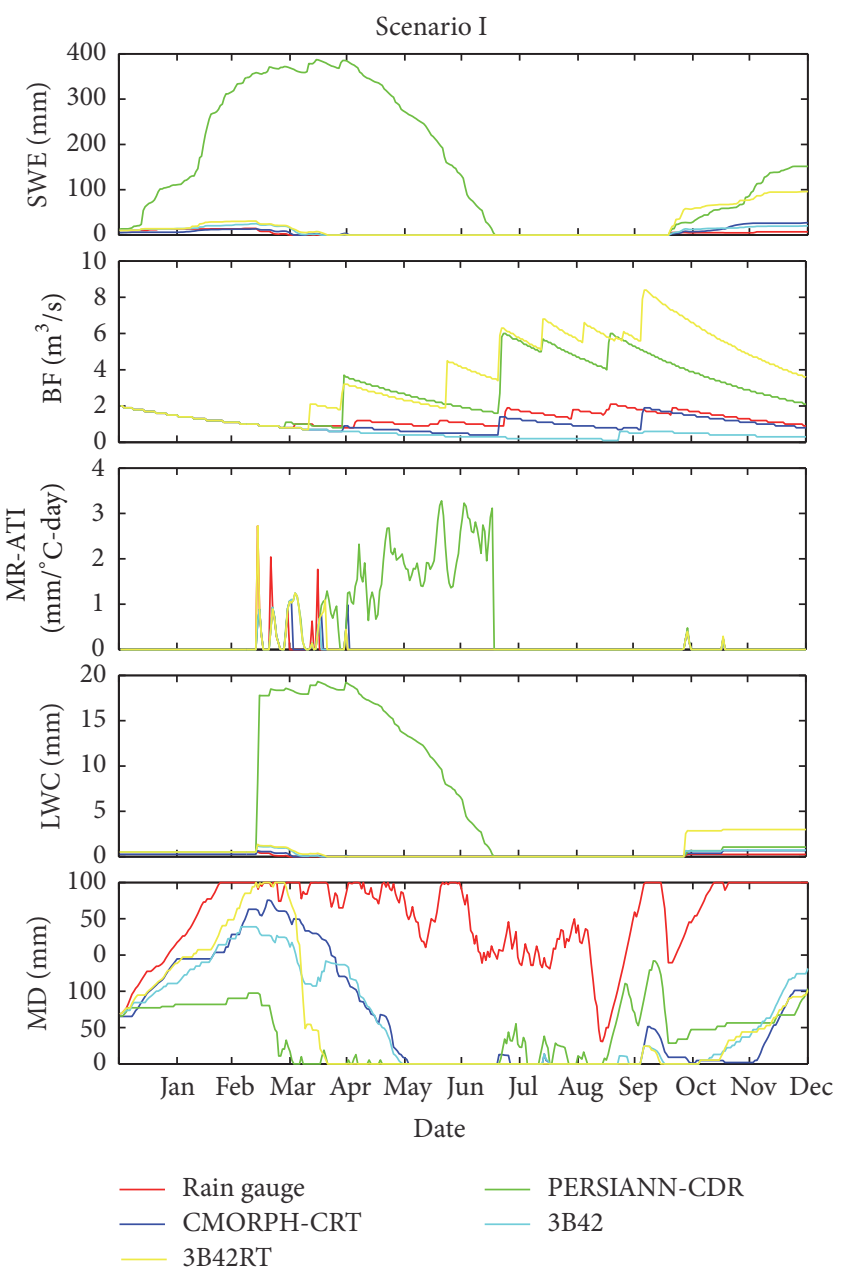

(a)
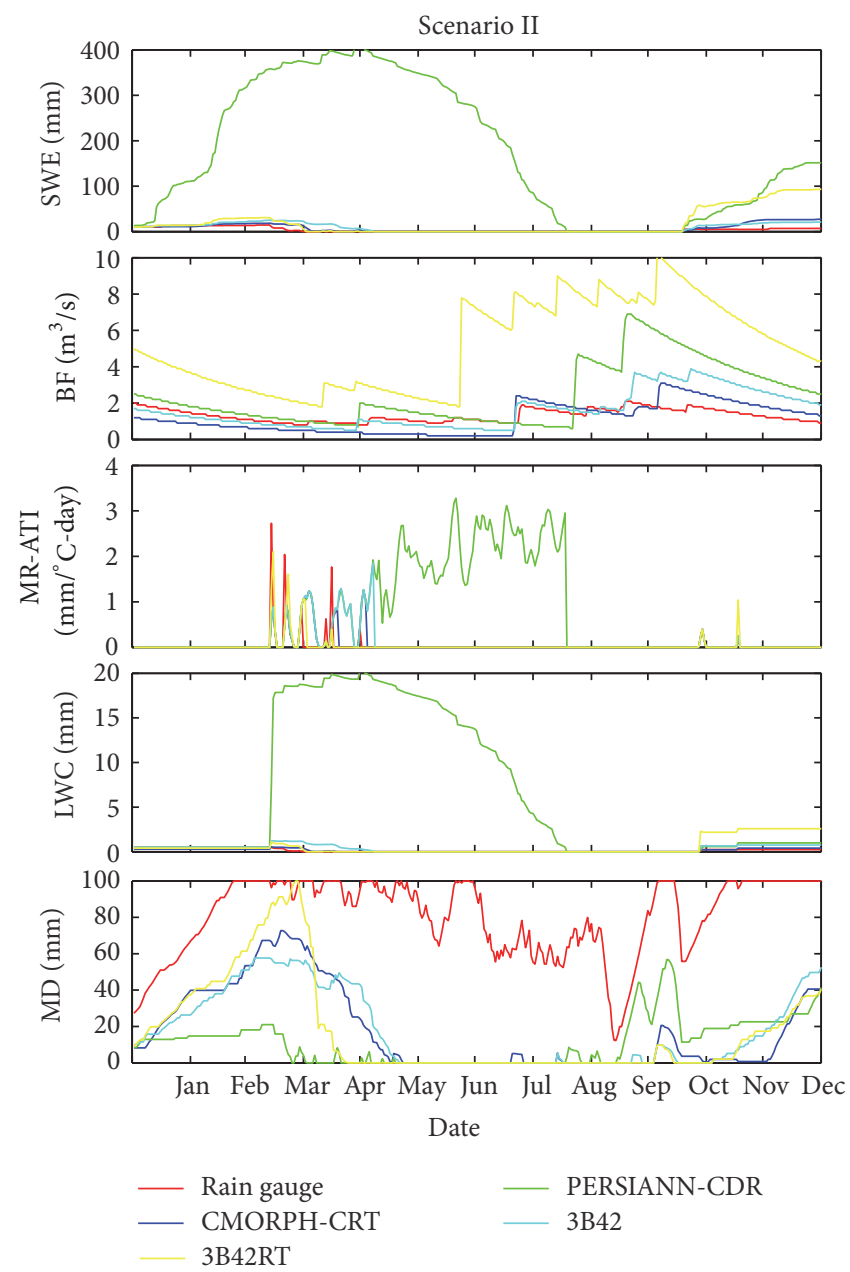

(b)

FIGURE 11: SWE, BF, MR-ATI, LWC, and MD derived by HEC-HMS model with the four-satellite and gauged precipitation data as forcing inputs under scenario I (a) and scenario II (b) in the dray year 2008.

and 3B42 slightly underestimate precipitation, while PERSIANN-CDR and 3B42RT show strong overestimation. Moreover, all satellite products exhibit the poor performance in cold seasons, especially in the winter season, probably because the surfaces are covered with snow and ice.

(iii) This study found that there is difficulty in accurately estimating rainstorms based on satellite precipitation datasets over the GRB; CMORPH-CRT and 3B42 underestimate in the medium and high precipitation intensities ranges, and the opposite tendency is found for PERSIANN-CDR and 3B42RT. Among all products, CMORPH-CRT and 3B42 are closer to gauge precipitation data when the precipitation class range is over $1 \mathrm{~mm} /$ day, but they cannot be considered fully reliable, which may be due to the lack of adequate precipitation observations.

(iv) As precipitation intensity increases, most of the satellite-based precipitation products are better able to capture the magnitude of precipitation events. The precipitation detection performances of CMORPHCRT and 3B42 in all indices values are equivalent. However, CMORPH-CRT exhibits the best POD and CSI scores across all precipitation thresholds, but its FAR score is larger than that of 3B42 and 3B42RT. This implies that the monthly gauge adjustment scheme used in TRMM products is still superior over others.

(v) The obtained results of hydrologic modeling under the two scenarios in this study suggest that: In scenario I, 3B42-drived simulations with gaugedbenchmarked model parameter values yield comparable performance to gauge precipitation data in the calibration period, while the performance in the validation period is better than those based on satellite and gauged precipitation datasets as forcing inputs for the HEC-HMS model, suggesting that $3 \mathrm{~B} 42$ is more suitable to drive the HEC-HMS model for daily streamflow simulation over the GRB. By contrast, CMORPH-CRT, PERSIANN-CDR, and 3B42RT products have little potential for use in hydrological simulation over the GRB, especially 


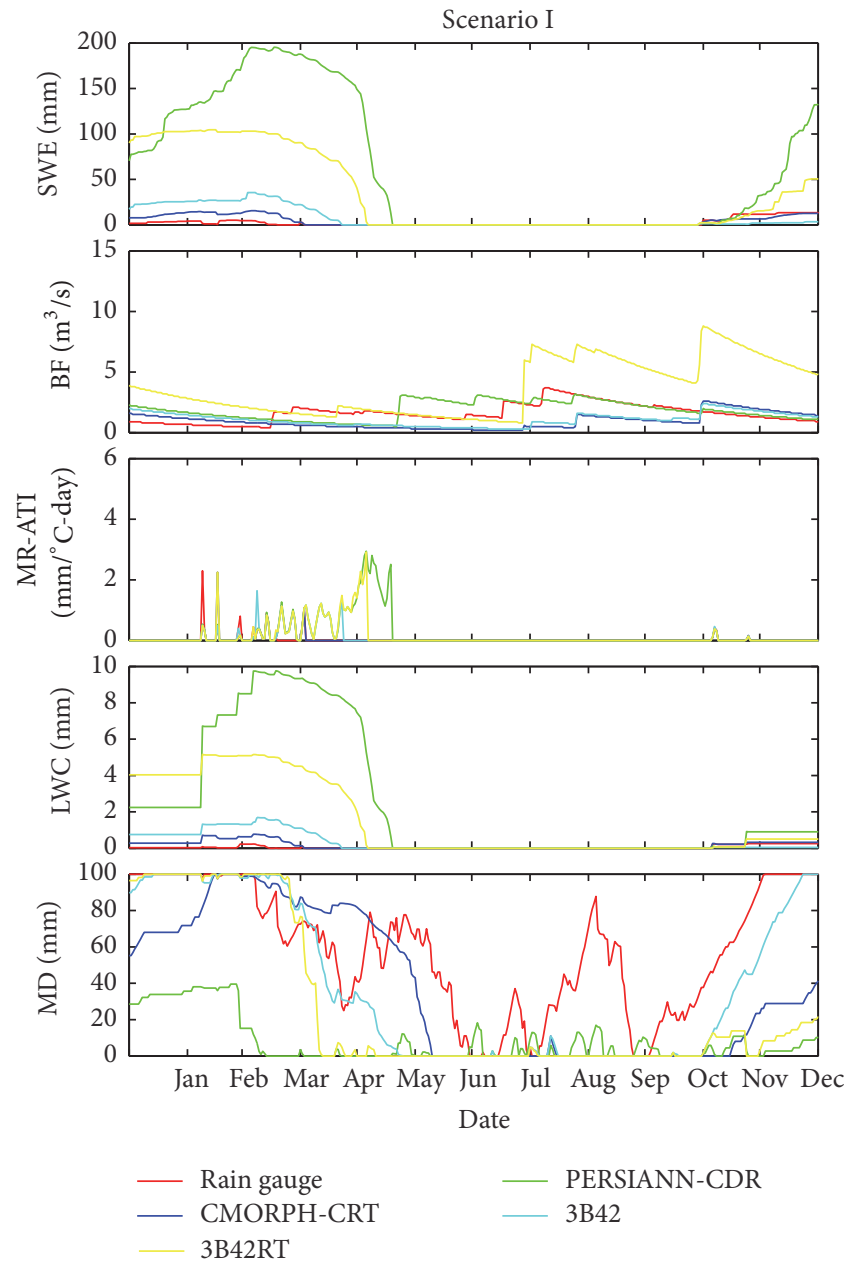

(a)
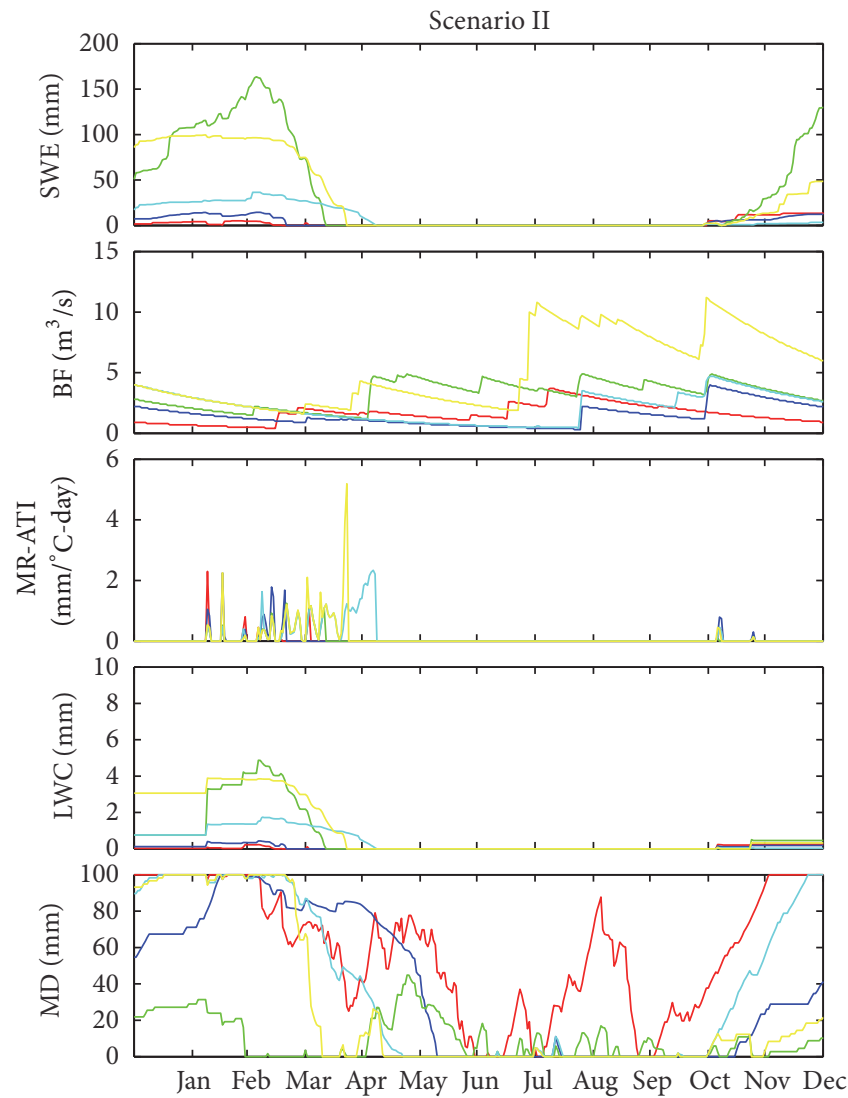

Date

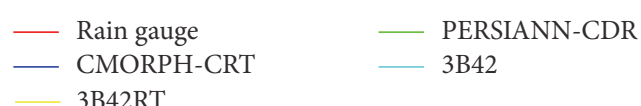

(b)

Figure 12: As in Figure 11, but in the wet year 2012.

PERSIANN-CDR, which shows the worst overall performance. In scenario II, all satellite precipitation forced simulations show substantially improved performance after recalibration, except for PERSIANNCDR during validation period. The results also suggest that 3B42 can be a potential alternative source of data sparse in the mountainous southeast Tibetan Plateau basins.

(vi) This study demonstrates that scenario II has the capability to compensate for erroneous satellite forcing through an increase or decrease of other hydrological components' values, such as SWE, BF, MR-ATI, LWC, and MD.

In conclusion, many efforts should be made to verify aspects of the overall deficiencies associated with the latest satellite precipitation products when they are applied to simulate the hydrological processes for other ungauged or sparsely gauged basins.

\section{Conflicts of Interest}

The authors declare that they have no conflicts of interest.

\section{Acknowledgments}

The research was supported by the National Basic Research Program of China (Grant no. 2013CBA01806); National Key Research and Development Program (Grant no. 2016YFA0601504); NNSF (Grant nos. 41571015, 41371049, 41323001, and 51539003); and the project of the State Key Laboratory of Hydrology-Water Resources and Hydraulic Engineering, China (Grant no. 20165042612).

\section{References}

[1] A. Behrangi, B. Khakbaz, T. C. Jaw, A. AghaKouchak, K. Hsu, and S. Sorooshian, "Hydrologic evaluation of satellite precipitation products over a mid-size basin," Journal of Hydrology, vol. 397, no. 3-4, pp. 225-237, 2011.

[2] A. H. Siddique-E-Akbor, F. Hossain, S. Sikder et al., "Satellite precipitation data-driven hydrological modeling for water resources management in the Ganges, Brahmaputra, and Meghna Basins," Earth Interactions, vol. 18, no. 17, pp. 1-25, 2014.

[3] Y. M. Mohamoud and L. M. Prieto, "Effect of temporal and spatial rainfall resolution on HSPF predictive performance and parameter estimation," Journal of Hydrologic Engineering, vol. 17, no. 3, pp. 377-388, 2012. 
[4] H. Xu, C.-Y. Xu, H. Chen, Z. Zhang, and L. Li, "Assessing the influence of rain gauge density and distribution on hydrological model performance in a humid region of China," Journal of Hydrology, vol. 505, pp. 1-12, 2013.

[5] H. Vergara, Y. Hong, J. J. Gourley et al., "Effects of resolution of satellite-based rainfall estimates on hydrologic modeling skill at different scales," Journal of Hydrometeorology, vol. 15, no. 2, pp. 593-613, 2014.

[6] H. Ashouri, P. Nguyen, A. Thorstensen, K.-L. Hsu, S. Sorooshian, and D. Braithwaite, "Assessing the efficacy of high-resolution satellite-based PERSIANN-CDR precipitation product in simulating streamflow," Journal of Hydrometeorology, vol. 17, no. 7, pp. 2061-2076, 2016.

[7] J. Zhang, K. Howard, C. Langston et al., "National mosaic and multi-sensor QPE (NMQ) system: description, results, and future plans," Bulletin of the American Meteorological Society, vol. 92, no. 10, pp. 1321-1338, 2011.

[8] K. Tong, F. Su, D. Yang, L. Zhang, and Z. Hao, “Tibetan Plateau precipitation as depicted by gauge observations, reanalyses and satellite retrievals," International Journal of Climatology, vol. 34, no. 2, pp. 265-285, 2014.

[9] Y. Ma, Y. Zhang, D. Yang, and S. B. Farhan, "Precipitation bias variability versus various gauges under different climatic conditions over the Third Pole Environment (TPE) region," International Journal of Climatology, vol. 35, no. 7, pp. 1201-1211, 2015.

[10] R. R. E. Vernimmen, A. Hooijer, Mamenun, E. Aldrian, and A. I. J. M. Van Dijk, "Evaluation and bias correction of satellite rainfall data for drought monitoring in Indonesia," Hydrology and Earth System Sciences, vol. 16, no. 1, pp. 133-146, 2012.

[11] X. Xue, Y. Hong, A. S. Limaye et al., "Statistical and hydrological evaluation of TRMM-based Multi-satellite Precipitation Analysis over the Wangchu Basin of Bhutan: are the latest satellite precipitation products 3B42V7 ready for use in ungauged basins?" Journal of Hydrology, vol. 499, pp. 91-99, 2013.

[12] G. Villarini, W. F. Krajewski, and J. A. Smith, "New paradigm for statistical validation of satellite precipitation estimates: application to a large sample of the TMPA $0.25^{\circ}$ 3-hourly estimates over Oklahoma," Journal of Geophysical Research, vol. 114, Article ID D12106, 2009.

[13] T. Dinku, F. Ruiz, S. J. Connor, and P. Ceccato, "Validation and intercomparison of satellite rainfall estimates over Colombia," Journal of Applied Meteorology and Climatology, vol. 49, no. 5, pp. 1004-1014, 2010.

[14] M. M. Bitew and M. Gebremichael, "Evaluation of satellite rainfall products through hydrologic simulation in a fully distributed hydrologic model," Water Resources Research, vol. 47, no. 6, Article ID W06526, 2011.

[15] M. M. Bitew, M. Gebremichael, L. T. Ghebremichael, and Y. A. Bayissa, "Evaluation of high-resolution satellite rainfall products through streamflow simulation in a hydrological modeling of a small mountainous watershed in Ethiopia," Journal of Hydrometeorology, vol. 13, no. 1, pp. 338-350, 2012.

[16] B. Peng, J. Shi, W. Ni-Meister, T. Zhao, and D. Ji, "Evaluation of TRMM multisatellite precipitation analysis (TMPA) products and their potential hydrological application at an arid and semiarid basin in china," IEEE Journal of Selected Topics in Applied Earth Observations and Remote Sensing, vol. 7, no. 9, pp. 3915-3930, 2014.

[17] R. Sun, H. Yuan, X. Liu, and X. Jiang, "Evaluation of the latest satellite-gauge precipitation products and their hydrologic applications over the Huaihe River basin," Journal of Hydrology, vol. 536, pp. 302-319, 2016.

[18] B. Yong, D. Liu, J. J. Gourley et al., "Global view of real-time TRMM multisatellite precipitation analysis: implications for its successor global precipitation measurement mission," Bulletin of the American Meteorological Society, vol. 96, no. 2, pp. 283296, 2015.

[19] V. Thiemig, R. Rojas, M. Zambrano-Bigiarini, and A. De Roo, "Hydrological evaluation of satellite-based rainfall estimates over the Volta and Baro-Akobo Basin," Journal of Hydrology, vol. 499, pp. 324-338, 2013.

[20] J. Joyce, P. Xie, Y. Yarosh, J. E. Janowiak, and P. A. Arkin, "CMORPH: a 'morphing' approach for high resolution precipitation product generation," in Satellite Rainfall Applications for Surface Hydrology, M. Gebremichael and F. Hossain, Eds., pp. 23-37, Springer, Dordrecht, The Netherlands, 2010.

[21] H. Ashouri, K.-L. Hsu, S. Sorooshian et al., "PERSIANNCDR: daily precipitation climate data record from multisatellite observations for hydrological and climate studies," Bulletin of the American Meteorological Society, vol. 96, no. 1, pp. 69-83, 2015.

[22] G. J. Huffman, R. F. Adler, D. T. Bolvin et al., "The TRMM multisatellite precipitation analysis (TMPA): quasi-global, multiyear, combined-sensor precipitation estimates at fine scales," Journal of Hydrometeorology, vol. 8, pp. 38-55, 2007.

[23] Y. C. Gao and M. F. Liu, "Evaluation of high-resolution satellite precipitation products using rain gauge observations over the Tibetan Plateau," Hydrology and Earth System Sciences, vol. 17, no. 2, pp. 837-849, 2013.

[24] Z. Li, D. Yang, and Y. Hong, "Multi-scale evaluation of highresolution multi-sensor blended global precipitation products over the Yangtze River," Journal of Hydrology, vol. 500, pp. 157169, 2013.

[25] S.-H. Jiang, M. Zhou, L.-L. Ren, X.-R. Cheng, and P.-J. Zhang, "Evaluation of latest TMPA and CMORPH satellite precipitation products over Yellow River Basin," Water Science and Engineering, vol. 9, no. 2, pp. 87-96, 2016.

[26] X. Liu, T. Yang, K. Hsu, C. Liu, and S. Sorooshian, "Evaluating the streamflow simulation capability of PERSIANN-CDR daily rainfall products in two river basins on the Tibetan Plateau," Hydrology and Earth System Sciences Discussions, vol. 21, no. 1, 2016.

[27] D. Li, X. Ding, and J. Wu, "Simulating the regional water balance through hydrological model based on TRMM satellite rainfall data," Hydrology and Earth System Sciences, vol. 12, no. 2, pp. 2497-2525, 2015.

[28] E. I. Nikolopoulos, E. N. Anagnostou, F. Hossain, M. Gebremichael, and M. Borga, "Understanding the scale relationships of uncertainty propagation of satellite rainfall through a distributed hydrologic model," Journal of Hydrometeorology, vol. 11, no. 2, pp. 520-532, 2010.

[29] R. Grayson and G. Bloschl, Spatial Patterns in Catchment Hydrology: Observations and Modelling, Cambridge University Press, Cambridge, UK, 2001.

[30] R. J. Joyce, J. E. Janowiak, P. A. Arkin, and P. Xie, "CMORPH: A method that produces global precipitation estimates from passive microwave and infrared data at high spatial and temporal resolution," Journal of Hydrometeorology, vol. 5, no. 3, pp. 487503, 2004.

[31] P. Xie, R. Joyce, and S. Wu, "A 15-year high-resolution gauge-satellite merged analysis of precipitation," in Proceedings of the 27th Conference on Hydrology, 3B.4, American 
Meteorological Society, Austin, Tex, USA, 2013, https://ams .confex.com/ams/93Annual/webprogram/Paper220506.html.

[32] P. P. Xie, S. H. Yoo, R. Joyce, and Y. Yarosh, "Bias-corrected CMORPH: a 13-year analysis of high-resolution global precipitation," Geophysical Research Abstracts, vol. 13, Article ID EGU2011-1809, 2011.

[33] K.-L. Hsu, X. Gao, S. Sorooshian, and H. V. Gupta, "Precipitation estimation from remotely sensed information using artificial neural networks," Journal of Applied Meteorology, vol. 36, no. 9, pp. 1176-1190, 1997.

[34] S. Sorooshian, K.-L. Hsu, X. Gao, H. V. Gupta, B. Imam, and D. Braithwaite, "Evaluation of PERSIANN system satellitebased estimates of tropical rainfall," Bulletin of the American Meteorological Society, vol. 81, no. 9, pp. 2035-2046, 2000.

[35] K. R. Knapp, "Scientific data stewardship of international satellite cloud climatology project B1 global geostationary observations," Journal of Applied Remote Sensing, vol. 2, no. 1, Article ID 023548, 2008.

[36] C. Miao, H. Ashouri, K.-L. Hsu, S. Sorooshian, and Q. Duan, "Evaluation of the PERSIANN-CDR daily rainfall estimates in capturing the behavior of extreme precipitation events over China," Journal of Hydrometeorology, vol. 16, no. 3, pp. 13871396, 2015.

[37] C. Kummerow, W. Barnes, T. Kozu, J. Shiue, and J. Simpson, "The Tropical Rainfall Measuring Mission (TRMM) sensor package," Journal of Atmospheric and Oceanic Technology, vol. 15, no. 3, pp. 809-817, 1998.

[38] G. J. Huffman and D. T. Bolvin, TRMM and Other Data Precipitation Data Set Documentation, Laboratory for Atmospheres, NASA Goddard Space Flight Center and Science Systems and Applications, 2012.

[39] G. J. Huffman, R. F. Adler, D. T. Bolvin, and E. J. Nelkin, "The TRMM multi-satellite precipitation analysis (TMPA)," in Satellite Rainfall Applications for Surface Hydrology, M. Gebremichael and F. Hossain, Eds., pp. 3-22, Springer, Dordrecht, The Netherlands, 2010.

[40] G. J. Huffman and D. T. Bolvin, "TRMM and other data precipitation data set documentation," Global Change Master Directory, NASA, 2013, ftp://precip.gsfc.nasa.gov/pub/trmmdocs/ 3B42_3B43_doc.pdf.

[41] G. J. Huffman and D. T. Bolvin, TRMM and Other Data Precipitation Data Set Documentation, NASA Global Change Master Directory Doc, Mesoscale Atmospheric Processes Laboratory, 2015, http://pmm.nasa.gov/sites/default/files/document_ files/3B42_3B43_doc_V7.pdf.

[42] W. A. Scharffenberg, Hydrologic Modeling System HEC-HMS User's Manual, U.S. Army Corps of Engineers, Hydrologic Engineering Center (HEC), Davis, Calif, USA, 2013.

[43] A. D. Feldman, Hydrologic Modeling System HEC-HMS Technical Reference Manual, U.S. Army Corps of Engineers, Hydrologic Engineering Center (HEC), Davis, Calif, USA, 2000.

[44] K. Ibrahim-Bathis and S. A. Ahmed, "Rainfall-runoff modelling of Doddahalla watershed-an application of HEC-HMS and SCN-CN in ungauged agricultural watershed," Arabian Journal of Geosciences, vol. 9, no. 3, article no. 170, 2016.

[45] R. Kabiri, V. Ramani Bai, and A. Chan, "Assessment of hydrologic impacts of climate change on the runoff trend in Klang Watershed, Malaysia," Environmental Earth Sciences, vol. 73, no. 1, pp. 27-37, 2015.

[46] M. M. G. T. De Silva, S. B. Weerakoon, and S. Herath, "Modeling of event and continuous flow hydrographs with HEC-HMS: case study in the Kelani River basin, Sri Lanka," Journal of Hydrologic Engineering, vol. 19, no. 4, pp. 800-806, 2014.

[47] M. J. Fleming and J. H. Doan, HEC-GeoHMS Geospatial Hydrologic Modeling Extension, User's Manual Version 10.1, US Army Corps of Engineers, Hydrologic Engineering Center, Davis, Calif, USA, 2013.

[48] R. Gyawali and D. W. Watkins, "Continuous hydrologic modeling of snow-affected watersheds in the great lakes basin using HEC-HMS," Journal of Hydrologic Engineering, vol. 18, no. 1, pp. 29-39, 2013.

[49] R. Mahmood, S. Jia, and M. S. Babel, "Potential impacts of climate change on water resources in the kunhar river basin, Pakistan," Water (Switzerland), vol. 8, no. 1, article 23, 2016.

[50] H. Wheater, S. Sorooshian, and K. D. Sharma, Hydrological Modelling in Arid and Semi-Arid Areas, Cambridge University Press, 2008.

[51] A. B. Dariane, M. M. Javadianzadeh, and L. D. James, "Developing an efficient auto-calibration algorithm for HEC-HMS program," Water Resources Management, vol. 30, no. 6, pp. 19231937, 2016.

[52] S. Jiang, L. Ren, Y. Hong et al., "Comprehensive evaluation of multi-satellite precipitation products with a dense rain gauge network and optimally merging their simulated hydrological flows using the Bayesian model averaging method," Journal of Hydrology, vol. 452-453, pp. 213-225, 2012.

[53] D. N. Moriasi, J. G. Arnold, M. W. Van Liew, R. L. Bingner, R. D. Harmel, and T. L. Veith, "Model evaluation guidelines for systematic quantification of accuracy in watershed simulations," Transactions of the ASABE, vol. 50, no. 3, pp. 885-900, 2007.

[54] D. Wilks, Statistical Methods in the Atmospheric Sciences, Academic Press, 2nd edition, 2006.

[55] S. Wang, S. Liu, X. Mo et al., "Evaluation of remotely sensed precipitation and its performance for streamflow simulations in basins of the Southeast Tibetan Plateau," Journal of Hydrometeorology, vol. 16, no. 6, pp. 2577-2594, 2015.

[56] R. Sun, H. Yuan, X. Liu, and X. Jiang, "Evaluation of the latest satellite-gauge precipitation products and their hydrologic applications over the Huaihe River basin," Journal of Hydrology, vol. 536, pp. 302-319, 2016.

[57] W. Qi, C. Zhang, G. Fu, C. Sweetapple, and H. Zhou, "Evaluation of global fine-resolution precipitation products and their uncertainty quantification in ensemble discharge simulations," Hydrology and Earth System Sciences, vol. 20, no. 2, pp. 903-920, 2016. 

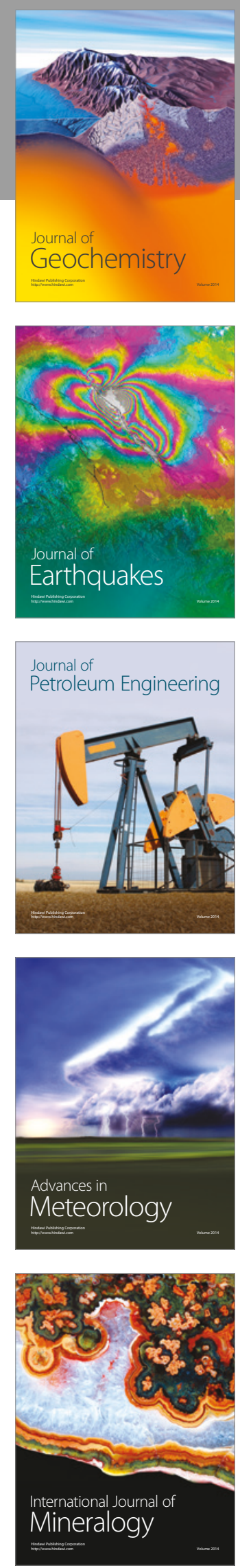
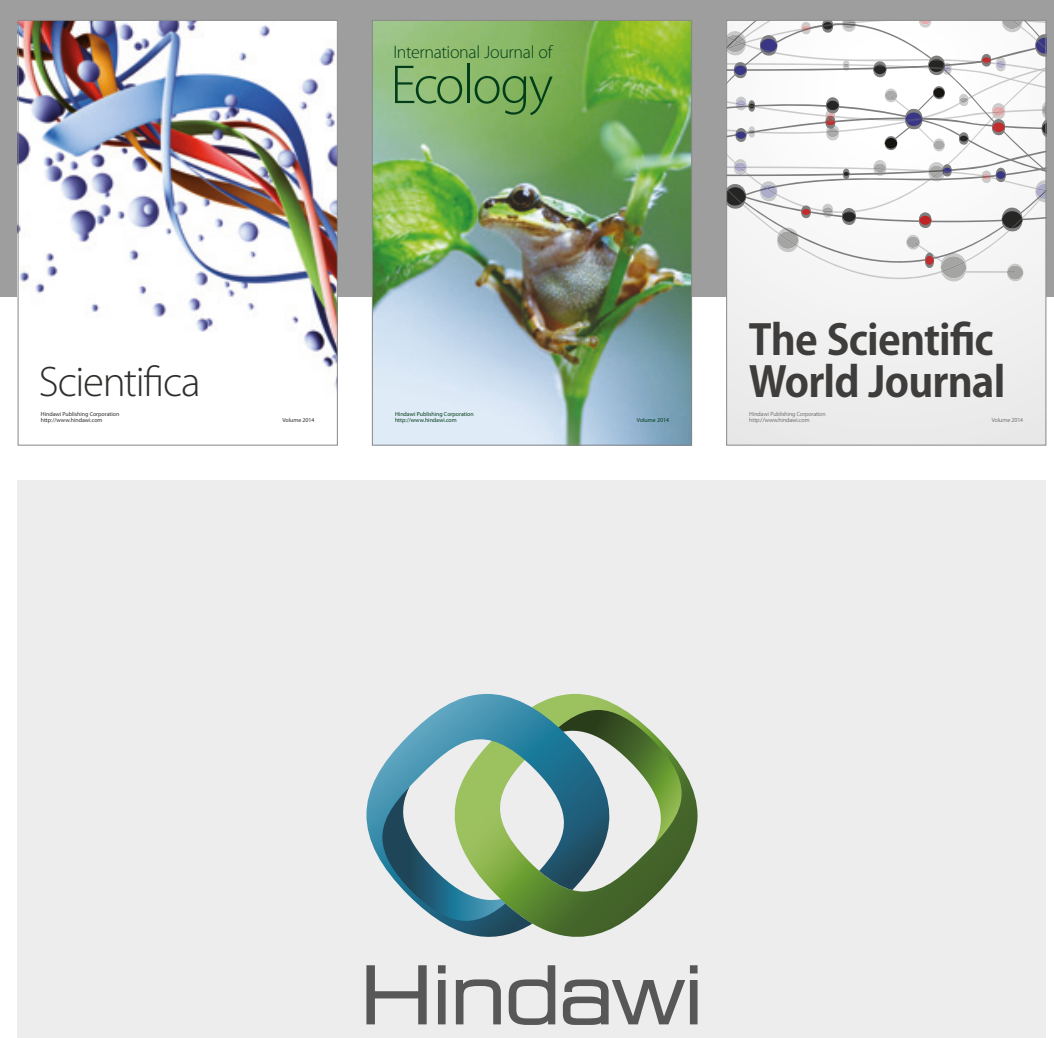

Submit your manuscripts at

https://www.hindawi.com
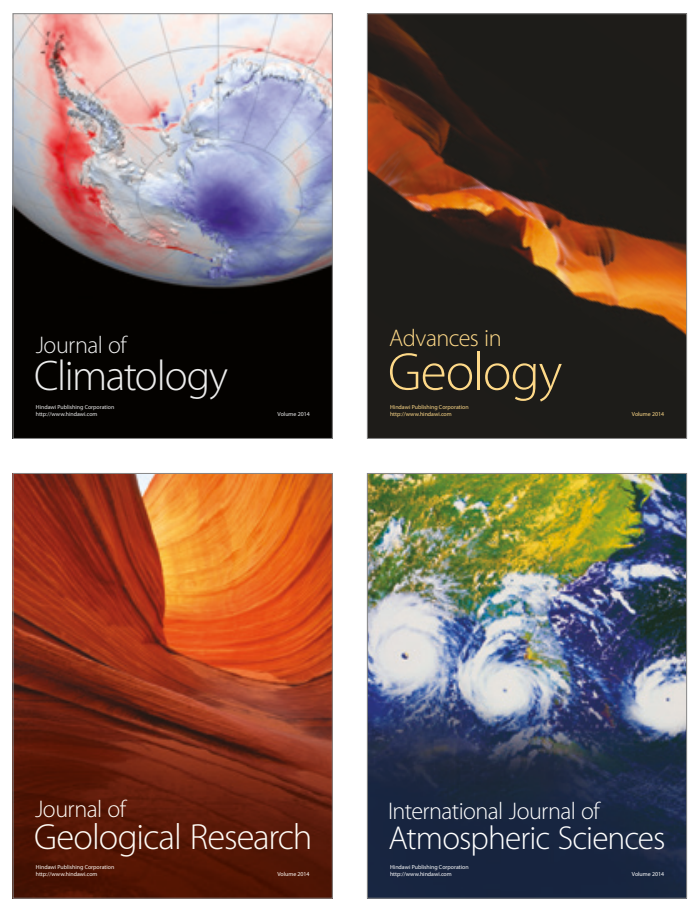

The Scientific

World Journal
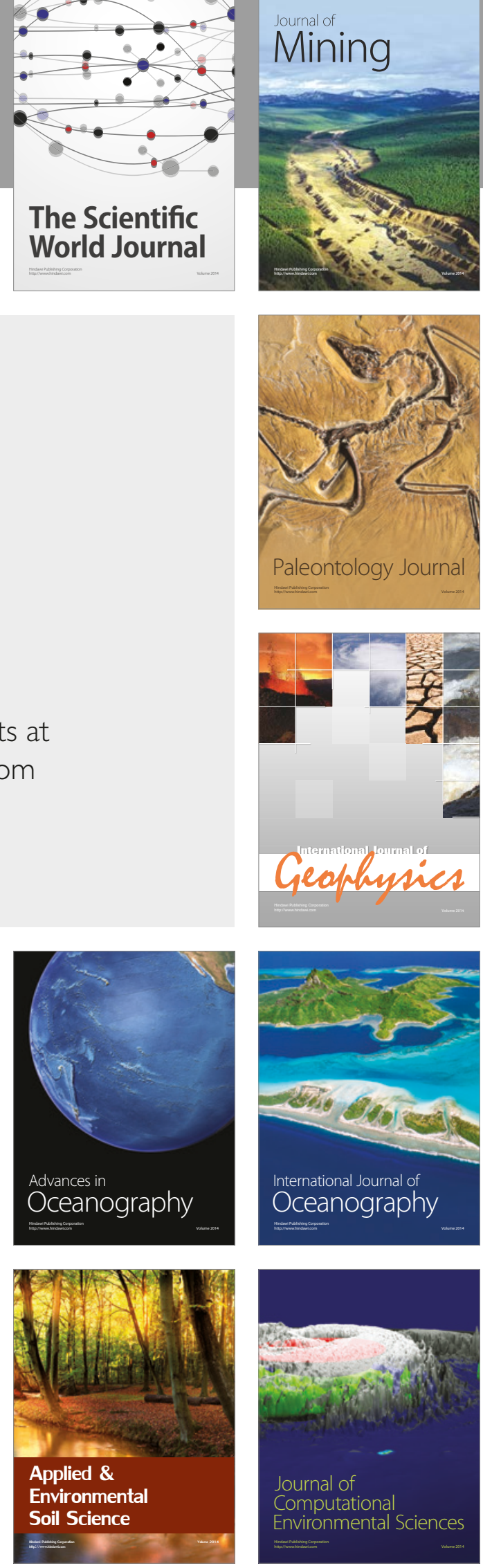